Article

\title{
Finding Solutions for Optimal Reactive Power Dispatch Problem by a Novel Improved Antlion Optimization Algorithm
}

\author{
Zelan Li ${ }^{1}$, Yijia Cao ${ }^{1}$, Le Van Dai ${ }^{2} \mathbb{D}$, Xiaoliang Yang ${ }^{1,3}$ and Thang Trung Nguyen ${ }^{4, *(\mathbb{D})}$ \\ 1 College of Electrical and Information Engineering, Hunan University, Changsha 410082, China \\ 2 Institute of Research and Development, Duy Tan University, Da Nang 550000, Vietnam \\ 3 College of Electrical and Information Engineering, Zhengzhou University of Light Industry, \\ Zhengzhou 450002, China \\ 4 Power System Optimization Research Group, Faculty of Electrical and Electronics Engineering, \\ Ton Duc Thang University, Ho Chi Minh City 700000, Vietnam \\ * Correspondence: nguyentrungthang@tdtu.edu.vn; Tel.: +84-986-515-857
}

Received: 19 June 2019; Accepted: 28 July 2019; Published: 1 August 2019

\begin{abstract}
In this paper, a novel improved Antlion optimization algorithm (IALO) has been proposed for solving three different IEEE power systems of optimal reactive power dispatch (ORPD) problem. Such three power systems with a set of constraints in transmission power networks such as voltage limitation of all buses, limitations of tap of all transformers, maximum power transmission limitation of all conductors and limitations of all capacitor banks have given a big challenge for global optimal solution search ability of the proposed method. The proposed IALO method has been developed by modifying new solution generation technique of standard antlion optimization algorithm (ALO). By optimizing three single objective functions of systems with 30,57 and 118 buses, the proposed method has been demonstrated to be more effective than ALO in terms of the most optimal solution search ability, solution search speed and search stabilization. In addition, the proposed method has also been compared to other existing methods and it has obtained better results than approximately all compared ones. Consequently, the proposed IALO method is deserving of a potential optimization tool for solving ORPD problem and other optimization problems in power system optimization fields.
\end{abstract}

Keywords: antlion optimization algorithm; optimal reactive power dispatch; IEEE power systems; power loss; voltage deviation; voltage stability index

\section{Introduction}

Optimal reactive power dispatch (ORPD) is an important optimization operation problem in power system field. ORPD can enable power systems to work stably and economically by setting the most appropriate parameters for electric components such as tap changer value of transformers, reactive power generation of capacitors and voltage magnitude of generators. In addition, the ORPD problem also considers all constraints from these components and other components in a real transmission power network such as reactive power generation limitation and voltage magnitude of generators at electric power plants, reactive power generation limitations of capacitors, working voltage of loads and apparent power limitation of feeders. Compared to optimal power flow (OPF) problem, ORPD problem considers active power generation of electric power plants as known parameters. Thus, it can be sated that the ORPD problem is simpler than the OPF problem because it owns a smaller number of control variables that have to be tuned optimally. However, ORPD problem has played a very highly important role for the case that active power flow in transmission power network is highly effective but reactive power flow currently cause negative impact on loads or other components. The ORPD 
problem is very useful for this case. Similar to the OPF problem, the ORPD problem also focuses on optimization of major objectives like reduction of active power losses on all feeders, minimization of voltage deviation of load buses and enhancement of voltage stabilization.

Difficulties of setting the most appropriate parameters for electric components have inspired researchers to propose optimization algorithms as well as constraint handling methods. Between these methods, optimization algorithms are in charge of determining optimal values for control variables while constraint handling methods support these optimization methods to deal with limitations effectively. There were a huge number of optimization algorithms that were applied for the ORPD problem and resulted in good solutions. These methods are the evolutionary programming method (EPM) [1], the modified hybrid evolutionary programming method (MHEPM) [2], differential evolution (DE) [3,4], a combination of iterative method and differential evolutionary method (CIDE) [5], the improved differential evolutionary method (IDE) [6], the adaptive genetic algorithm (AGA) [7], the self-adaptive real coded genetic algorithm (SARCGA) [8], the particular genetic algorithm (PGA) [9], the particle swarm optimization (PSO) with inertia weight factor (WPSO) [10], PSO with an aging leader and challengers (PSO-ALC) [11], PSO with improved pseudo-gradient search (PSO-IPGS) [12], and PSO hybridize with imperialist competitive algorithm (PSO-ICA) [13]. In [1], EPM has successfully dealt with an IEEE 30-bus system for the case of reducing active power losses objective. It has been demonstrated that EPM was more effective than the Broyden-Fletcher-Goldfard-Shanno method (BFGS) for ORPD by obtaining smaller total power losses obtained by the method has been less than that from EPM and BFGS. However, the result from the method was not the best solution because other methods could continue to reduce the total power losses. MHEPM in [2] was the combination of the improved evolutionary programming method (IEPM) and the interior point method (IPM). In such a method, authors have applied the primal dual algorithm to create an initial solution for IEPM. Such a solution had a better fitness function value than other ones, leading its position nearby the position of the global optimal solution. By applying the strategy, MHEPM has become more efficient than EPM and IEPM regarding global search ability and fast convergence. Differential evolution (DE) is also a population-based optimization method developed in 1997. DE involves three mechanisms, namely mutation, crossover and selection, in which the mutation mechanism is the most important operator for creating good solutions. DE has been applied to handle a high number of optimization problems in the power system field. In [3,4]; the ORPD problem has been solved by conventional DE with different objectives on different test systems. DE [3] has been executed on standard IEEE 14, 30, 57 and 118-bus systems by considering the reduction of total active power losses while DE [4] has been tested on only a standard IEEE 30-bus system with three objectives including active power losses in all transmission lines, voltage deviations and voltage stability indexes. However, the achieved solution quality was not good enough for concluding the real performance of the method. Therefore, different improved versions of DE have been constantly developed for unraveling the shortcomings. In [6], authors have suggested a new formula for the mutation operation by using two modifications. The first modification was to use the best solution to replace a randomly selected solution meanwhile the second modification was to employ a new random mutation factor different from DE in $[3,4]$. The genetic algorithm (GA) is a famous optimization technique proposed in 1975 by John Holland. The main structure of GA is the same as DE but the crossover operator is considered as the most important role for producing good solutions. GA has suffered from the main shortcoming of easily falling into ineffective search zones with low quality solutions owing to the use of roulette-wheel selection. For that reason, many variants of GA have been developed by improving techniques of GA or by combing GA and other methods [7-9]. In [9], particularly the genetic algorithm (PGA), together with a novel constraint handling strategy, have been combined for finding optimal solutions for the ORPD problem. PGA has been supported by applying two penalty function approaches and its solution search ability has been tested on IEEE 30, 57, 118 and 300-bus power systems for performance comparisons. In addition to existing GA and DE variants, PSO is also an effective method by possessing simple structure, easy implementation and high efficiency. In PSO, each particle in population is represented by velocity and position. In the first 
stage, velocity is updated by using the best solution of the whole population and the best solution of each current solution. In the second stage, new position is found by using the previous and the new velocity. PSO has suffered from some disadvantages such as weak search ability in large search zones and premature convergence to local optimum. To overcome the drawbacks, researchers have given different solutions to reinforce the low performance of PSO as presented [10-13]. Study [10] has applied WPSO and Tabu search algorithm (TSA) for IEEE 14-bus system and IEEE 112-bus system with the objective of minimizing total power losses. WPSO has been considered to be more effective by finding solutions with lower power losses but there has not been comparison with other methods. PSO-IPGS [12] was an effective version of PSO by using pseudo-gradient search method to determine an effective direction. As a result, the method has found good solutions with high quality. By testing on IEEE 30 and 118-bus system for result comparisons, PSO-IPGS was stated to be more effective and robust than other PSO methods.

In addition to the implementation of popular methods like DE, PSO and GA for solving the ORPD problem, other methods have been applied such as seeker optimization algorithm (SOA) [14], harmony search algorithm (HSA) [15], gravitational search algorithm (GSA) [16], quasi-oppositional teaching learning based optimization algorithm (QOTLBOA) [17], chaotic krill herd algorithm (CKHA) [18], antlion optimizer (ALO) [19], multi-objective antlion optimization (MOALO) [20], differential search algorithm (DSA) [21], integrated strategies of Backtracking search (BSO) [22], whale optimization algorithm (WOA) [23], Gaussian bare-bones water cycle algorithm (GBWCA) [24], multi-objective grey wolf optimizer (MOGWA) [25], modified colliding bodies optimization algorithm (MCBOA) [26], moth-flame optimization method (MFOM) [27], Jaya optimization algorithm (JAYA) [28], social spider optimization algorithm (SSO) [29], modified social spider optimization algorithm (MSSO) [29], improved sine cosine algorithm (ISCA) [30], enhanced Jaya optimization technique (EJOT) [31] and adaptive chaotic symbiotic organisms search (ACSOSM) [32]. These methods were proposed for determining the perfect control variables in order to optimize objective functions. Among these algorithms, MSSO [29] is the latest algorithm. In [29], authors have stated that SSO was a powerful optimization tool by possessing three new solution generations but there were some equations with low performance in producing solutions. Thus, they have modified some of the equations. The modifications were mainly carried out in the three generations with the purpose of improving quality of new solutions, reducing computation steps as well as shortening simulation time. MSSO has been compared to both SSO and many existing methods by optimizing power losses, voltage deviation and voltage stability from IEEE 30 and 118-bus systems. Evidences such as lower power loss, smaller voltage deviation and better voltage stability have been obtained from the results of MSSO as compared to other methods. However, the method has still owned high number of computation steps in its structure.

In this paper, a novel method, called improved Antlion optimization algorithm (IALO), is applied for resolving optimal reactive power dispatch (ORPD) problem taking into consideration three different objective functions of different IEEE power systems. IALO is established by improving the structure of Antlion optimizer (ALO). ALO, a member of meta-heuristic algorithm family, has been inspired from a food finding activity of antlions in nature [33]. ALO was first developed by Mirjalili and used to solve different nineteen benchmark optimization functions in the first application. Via the result comparisons obtained from different test systems, the author revealed that ALO found promising results and outperformed other algorithms such as PSO, the States of Matter Search (SMS) algorithm, Bat algorithm (BA), Flower Pollination Algorithm (FPA), Cuckoo Search algorithm and Firefly Algorithm (FA). However, this method has some weaknesses in its structure, such as using roulette wheel technique and complicated formulas for updating new position of ants. The roulette wheel selection technique focuses on keeping promising solutions and exploiting local optimal zones. Thus, it is highly effective for simple problems with small number of control variables, simple constraints as well as narrow search spaces. However, the technique is limited for more complicated problems with high number of control variables, complicated constraints and large search spaces. Basically, ALO must cope with 
the main drawback of premature convergence due to the selection technique. Furthermore, for newly updated position of ants, many formulas with randomization are used, leading to time consuming issue. In IALO, we propose two improvements to cover such mentioned shortcomings. In the first improvement, a new technique is proposed to replace roulette wheel technique. Instead of using good solutions and eliminating worse solutions, the new technique divides all solutions into potential group and non-potential group based on comparison of fitness function. In the second improvement, new formulas are suggested for updating new position of ants to speed up search process, shorten a number of computation steps, as well as reduce implementation time. As mentioned above, almost all methods have advantages and disadvantages; however, their main shortcomings are about the real performance for ORPD problem with large scale systems and a high number of constraints. Many methods have successfully dealt with the ORPD problem and obtained interesting results, but they have been run by employing high population size and the high number of iterations. In addition, several methods have suffered from local optimal zones and hardly ever jumped out the zones for reaching near global optimum or global optimum. Some of the methods have shown very good results and have been considered to be more effective than other ones but sufficient evidences for the conclusions have not been clearly clarified. In fact, both the setting of control parameters as well as demonstration of faster speed and valid solutions have been ignored completely. On the contrary, the proposed IALO method can tackle the main shortcomings from other methods and good proofs for leading to real evaluation on the high performance of the proposed method can be clearly clarified in the paper. The novelties and the main contributions of the paper are as follows:

1) Clearly describe the search procedure and point out shortcomings of ALO.

2) Propose two main improvements on ALO for avoiding hopeless outcomes of ALO and achieving outstanding performance over ALO and other methods.

3) Implement ALO and the proposed IALO for finding optimal solutions from three IEEE power systems with 30, 57 and 118 buses under the consideration of three objectives such as total power loss, total voltage deviation and voltage stabilization index (L-index).

4) The proposed IALO can find better solutions than ALO and other methods in terms of less total power losses, voltage deviation and L-index.

5) The proposed IALO can reduce computation iterations significantly as compared to ALO and other methods.

The remaining parts of the paper can be divided into five sections as follows: description of ORPD problem with objective functions and constraints is given in Section 2. All computation steps of ALO method are formulated and explained in Section 3. History of ALO variants and two proposed improvements of IALO method are shown in Section 4. Section 5 presents the computation steps for solving a typical ORPD problem by applying the proposed IALO method. Result comparisons of three IEEE power systems are performed in Section 6. Finally, Section 7 summarizes the whole work and concludes the performance of the proposed IALO. In addition, the References and Appendix are also two important parts in the article.

\section{Problem Formulation}

The ORPD problem is a combination of objectives and constraints regarding optimization operation of electric components in transmission grids. There are three important objectives considered in regard to minimizing active power loss in all branches, voltage deviation of all load buses and voltage enhancement. In addition, the ORPD problem also takes equality and inequality constraints into account. The mathematical formulation of the ORPD problem is described as follows.

\subsection{Objective Function}

Active power loss function: effects of technical and non-technical losses are certain to occur and impossible to be avoided in operation of transmission power girds. Hence, the best work that should 
be performed is to reduce the total power losses of all branches. The calculation of total power losses and the objective can be seen by the function of Equation (1) below:

$$
\operatorname{Min} P_{\text {loss }}=\sum_{k=1}^{N_{B}} \sum_{\substack{j=1 \\ j \neq k}}^{N_{B}} g_{k j}\left[V o l_{k}^{2}+V o l_{j}^{2}-2 \operatorname{Vol}_{k} \operatorname{Vol}_{j} \cos \varphi_{k j}\right]
$$

where $g_{k j}$ and $\varphi_{k j}$ are the line conductance and the deviating angular between buses $k$ and $j$, respectively; $N_{B}$ is the total number of buses in the concerned power network.

Load bus voltage deviation function: voltage is an important criterion for evaluating power quality. Thus, the voltage's excessive change around expected value $1.0 \mathrm{pu}$ at load buses can result in unstably power system operation status affecting production process of manufactories, industrial zones as well as lifetime of electrical components. That is a reason leading to the significance of the second objective, which is to minimize total voltage deviation of all load buses in the considered system. The objective can be mathematically formulated by the following model:

$$
\operatorname{Min} T V D=\sum_{k=1}^{N_{L}}\left|V o l_{L k}-V o l_{r e f}\right|
$$

where $V o l_{L k}$ and $V o l_{r e f}$ are the voltage magnitude of the $k t h$ load bus and the expected voltage magnitude (normally $1.0 \mathrm{pu}$ ) for all load buses and $N_{L}$ is the number of load buses.

Voltage stability index (L-index): Improvement of voltage stability can enable power system avoid negative phenomena causing harmful impacts on electric components. Thus, the third objective function shown in Equations (3) and (4) is established to evaluate the working states of power system:

$$
\operatorname{Min} \text { L-index }=\max \left(L_{k}\right) ; k=1,2, \ldots, N_{B}
$$

In this case, the L-index of the power system is the maximum value of $L_{k}$, which is in range [0,1] and obtained by using Equation (4):

$$
L_{k}=\left|1-\frac{\sum_{j=1}^{N_{G}} Y_{k j} V o l_{j}}{V o l_{k}}\right|
$$

The power system operates stably and effectively at L-index value " 0 ". In contract, the L-index value can be close to " 1 " or even equal to " 1 " resulting in a couple of risks such as interruption of supplying power or even voltage collapse. Thus, the objective function in Equation (3) play a very important role in stability as well as economical issue of the considered power system.

\subsection{Considered Constraints}

\subsubsection{Equality Constraints}

In the ORPD problem, the equality constraints are reactive and active power balance conditions that are expressed by the meaning of Equations (5) and (6), respectively:

$$
A P_{G k}-A P_{d k}=\operatorname{Vol}_{k} \sum_{j=1}^{N_{B}} V_{j}\left[G_{k j} \cos \left(\varphi_{k}-\varphi_{j}\right)+B_{k j} \sin \left(\varphi_{k}-\varphi_{j}\right)\right] ; k=1, \ldots, N_{B}
$$




$$
R P_{G k}+R P_{c k}-R P_{d k}=V o l_{k} \sum_{j=1}^{N_{B}} V_{j}\left[G_{k j} \sin \left(\varphi_{k}-\varphi_{j}\right)-B_{k j} \cos \left(\varphi_{k}-\varphi_{j}\right)\right] ; i=1, \ldots, N_{B}
$$

If the two balance conditions are satisfied exactly, voltage and frequency of buses can be fixed and power system can be working stable.

\subsubsection{Inequality Constraints}

In the ORPD problem, the inequality constraints are mainly about the limitations of electric components such as generators, capacitors, transformers and conductors. These inequality constraints are specifically presented as follows.

Generator Constraints: Reactive power and voltage magnitude of generators are restricted inside lower and upper limits shown in Equations (7) and (8) below:

$$
\begin{gathered}
R P_{G_{k}, \min } \leq R P_{G_{k}} \leq R P_{G_{k}, \max } ; k=1, \ldots, N_{G} \\
V o l_{G k, \text { min }} \leq V o l_{G k} \leq V o l_{G k, \max } ; k=1, \ldots, N_{G}
\end{gathered}
$$

For assuring the satisfaction of the two constraints, voltage magnitude of generators is always controlled and corrected in case of violation whereas reactive power is penalized in case of violating the limitations. The detail of solving the constraints will be shown in Section 5. In addition, generators have another important factor, active power; however, in the ORPD problem, active power is predetermined and given as input data. The predetermined active power is also constrained by the following model:

$$
A P_{G k, \min } \leq A P_{G k} \leq A P_{G k, \max } ; k=1, \ldots, N_{G}
$$

Security constraints: other remaining inequality constraints of the system that should be taken into consideration are limitations of shunt VAR compensators, position of transformer tap, voltage magnitude of load and transmission branches. Such constraints are given in Inequalities (10)-(13) below:

$$
\begin{gathered}
R P_{c k, \text { min }} \leq R P_{c k} \leq R P_{c k, \text { max }} ; k=1, \ldots, N_{C} \\
T_{k, \text { min }} \leq T_{k} \leq T_{k, \text { max }} ; k=1, \ldots, N_{T} \\
V o l_{L k \text { min }} \leq V o l_{L k} \leq V o l_{L k, \text { max }} ; k=1, \ldots, N_{L} \\
S_{b} \leq S_{b, \text { max }}, \quad b=1,2, \ldots, N_{\text {branch }}
\end{gathered}
$$

\subsection{Control Variables}

In the ORPD problem, two sets of variable are considered to be control variables and dependent variables in which control variables are input data of Matpower program and dependent variables are results after running the program. The set of control variables $\left(S_{c v}\right)$ are as follows

- $\quad$ Voltage of generators (continuous variables)

- $\quad$ Tap changer values of transformers (continuous variables)

- $\quad$ Reactive power of capacitor banks (continuous variables)

\section{Conventional Antlion Optimization Algorithm (ALO)}

ALO was developed in 2015 by taking idea from the nature phenomenon of antlions and ants. The structure of ALO was presented in [33] and can be expressed in detail as follows. 


\subsection{Building Traps}

The process of building traps is known as the initialization of $N_{p}$ antlions. All the antlions are randomly produced within the upper and lower limitations as the following model:

$$
A L_{s}=A L_{\min }+\delta \times\left(A L_{\max }-A L_{\min }\right) ; s=1, \ldots, N_{p}
$$

where $A L_{\min }$ and $A L_{\max }$, respectively, are the lower and upper bounds of $N$ control variables and $\delta$ is a random number in range of [0,1]. In this paper, the best antlion owns the optimal fitness with minimum value. Moreover, the potential antlions corresponding to high-quality solutions, which are selected via roulette wheel technique, are retained for the next generation.

\subsection{Random Walking of Ants}

Ant species, favorite prey of the antlion, randomly moves to search food. Hence, the ants' position constantly changes in the space. Through the behavior, a random walk of each ant can be seen by the meaning of the following equation:

$$
R W_{s}^{I T}=\left[0, \sum_{I T=1}^{1} 2 \alpha_{I T}-1, \sum_{I T=1}^{2}\left(2 \alpha_{I T}-1\right), \sum_{I T=1}^{3}\left(2 \alpha_{I T}-1\right), \ldots, \sum_{I T=1}^{I T_{\max }}\left(2 \alpha_{I T}-1\right)\right]
$$

where $R W_{s}^{I T}$ is a matrix with size $\left(1 \times I T_{\max }\right)$ at the $I T$ th iteraiton and $\alpha_{I T}$ is considered as a moving factor and calculated by:

$$
\alpha_{I T}= \begin{cases}0 & \text { if } \varepsilon<0.5 \\ 1 & \text { else }\end{cases}
$$

where $\varepsilon$ is a random number uniformly distributed within the range of $[0,1]$.

\subsection{Trapped Ants}

The ALO is formulated based on interaction between antlions and ants in the trap. Because of the ants' random walk in the search space, the interaction seems difficult to form. Therefore, the ALO restricts the stochastic movement of preys by using the equation below:

$$
X A_{s}^{I T}=\left(\frac{R W_{s}^{I T}-R W_{s, \min }}{R W_{s, \max }-R W_{s, \min }}\right)\left(X A_{s, \text { max }}^{I T}-X A_{s, \min }^{I T}\right)+X A_{s, \text { min }}^{I T}
$$

where $X A_{s}^{I T}$ is a new position of the sth ant in the pit of the antlion selected by roulette wheel technique at the current iteration $I T ; R W_{s, \min }$ and $R W_{s, \max }$, respectively, are minimum and maximum of random walk of the sth ant; $X A_{s, \min }^{I T}$ and $X A_{s, \max }^{I T}$ indicate lower and upper limitations of all variables of the sth ant at the current iteration IT determined as follows:

$$
\begin{aligned}
& X A_{s, \text { min }}^{I T}=A L_{\text {rou }}^{I T}+\frac{A L_{\min }}{10^{w}} \times \frac{I T_{\max }}{I T} \\
& X A_{s, \text { max }}^{I T}=A L_{\text {rou }}^{I T}+\frac{A L_{\max }}{10^{w}} \times \frac{I T_{\max }}{I T}
\end{aligned}
$$

where $A L_{\text {rou }}^{I T}$ is an antlion selected by the roulette wheel technique at ITth iteation; $w$ is a constant and calculated based on the current iteration $\left(w=2\right.$ when $I T>0.1 I T_{\max }, w=3$ when $I T>0.5 I T_{\max }, w=4$ when $I T>0.75 I T_{\max }, w=5$ when $I T>0.9 I T_{\max }$ and $w=6$ when $\left.I T>0.95 I T_{\max }\right)$. 
In this algorithm, the ants' movement in the search space is also completely affected by the best antlion. Thus, every ant's position relating to pit of the best antlion is known as elite position and obtained by using Equation (20) below:

$$
X E_{s}^{I T}=\left(\frac{R W_{s}^{I T}-R W_{s, \min }}{R W_{s, \max }-R W_{s, \min }}\right)\left(X E_{s, \text { max }}^{I T}-X E_{s, \min }^{I T}\right)+X E_{s, \text { min }}^{I T}
$$

where $X E_{s, \min }^{I T}$ and $X E_{s, \max }^{I T}$ are the lower bound and upper bound of antlion's position at the ITth iteration obtained by the following equations:

$$
\begin{aligned}
& X E_{s, \text { min }}^{I T}=A L_{\text {best }}^{I T-1}+\frac{A L_{\min }}{10^{w}} \times \frac{I T_{\max }}{I T} \\
& X E_{s, \text { max }}^{I T}=A L_{\text {best }}^{I T-1}+\frac{A L_{\max }}{10^{w}} \times \frac{I T_{\max }}{I T}
\end{aligned}
$$

where $A L_{\text {best }}^{I T-1}$ is the position of the best antlion in the current population at the (IT - 1)th iteration.

As a result, the new position of each ant at the current iteration IT $\left(A n t_{s}^{I T}\right)$ is determined by the following model:

$$
A n t_{s}^{I T}=\frac{X A_{s}^{I T}+X E_{s}^{I T}}{2}
$$

\subsection{Catching Preys and Rebuilding Trap}

In the process, each antlion moves to the respective ant's position if the ant owns a better fitness value. The action can be expressed by the following equation:

$$
A L_{s}^{I T}=\left\{\begin{array}{l}
A n t_{s}^{I T} \text { if } \operatorname{Fit}\left(A n t_{s}^{I T}\right) \leq F i t\left(A L_{s}^{I T-1}\right) \\
A L_{s}^{I T-1} \text { else }
\end{array}\right.
$$

For minimization problems, $A n t_{s}^{I T}$ is a new solution and it is retained if its fitness function is smaller or equal to the fitness function of old solution $\left(A L_{s}^{I T-1}\right)$. On the contrary, old solution $A n t_{s}^{I T-1}$ is kept if its fitness function is lower than that of the new solution.

\subsection{The Whole Search Process of ALO Method}

Finally, the thus-far best antlion in each iteration is saved as the global of the problem. To aid comprehension, the search strategy of ALO is described in detail in the Figure 1 below: 


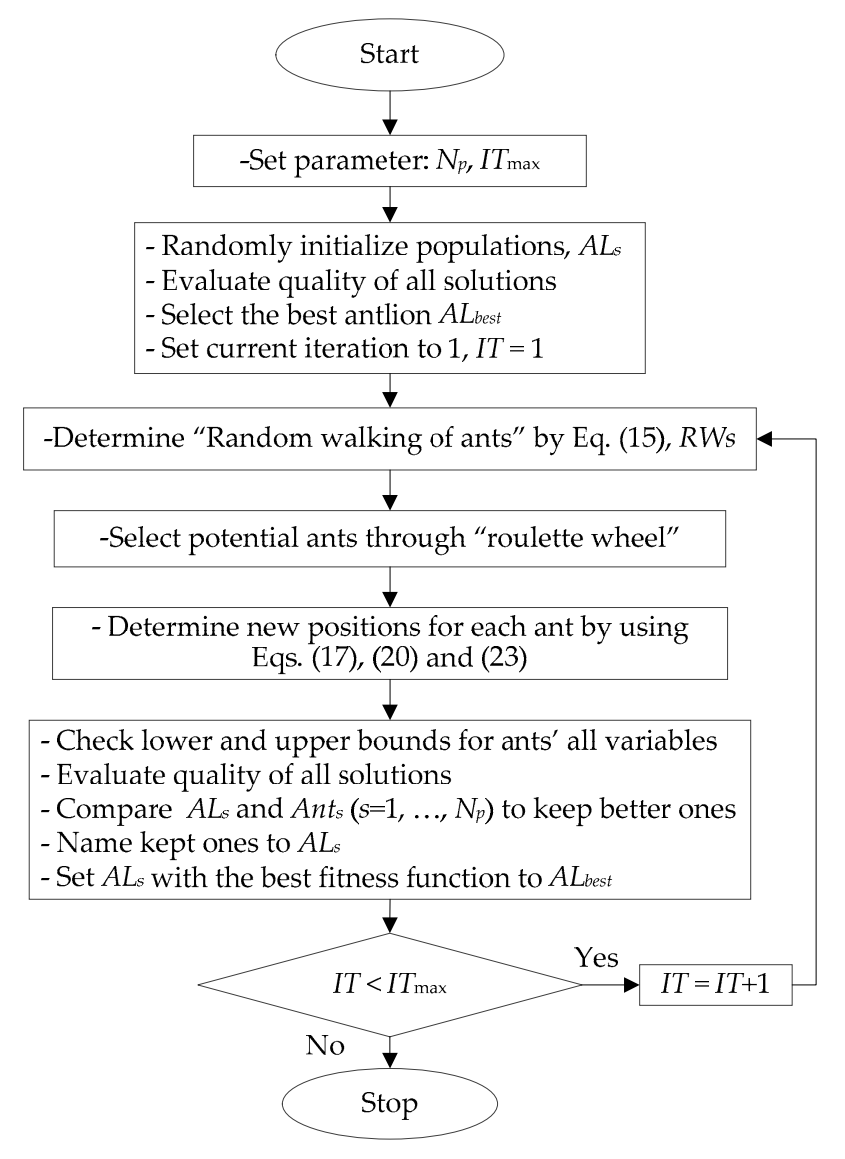

Figure 1. Flowchart of implementing Antlion Optimization algorithm.

\section{Improved Antlion Optimization Algorithm (IALO)}

\subsection{Review on Previous Improved Antlion Optimization Algorithm}

In recent years, most of the conventional population-based heuristic algorithms were created with the aim of solving complicated optimization problems. The series of benchmark functions became a popular study cases to test the operating quality of the algorithms. The results obtained by applying the new methods for handling benchmarks were extremely effective and optimized. However, the methods seem to cope with more difficulties in finding out a global solution for optimization operation problems with complicated constraints in power systems. Because of many search zones with local optimum solutions, the generated solutions in each iteration trend to fall into these local zones, which not only caused unexpected premature convergence but also consumed a huge number of iterations. Consequently, there were various improved Antlion Optimization algorithms published in previous studies in which each variant of the ALO was applied to minimize different objectives of different problems. An enhanced antlion optimization algorithm (EALO) [34] has applied a stochastic probability function instead of the uniform probability distribution function of original ALO. In addition, EALO has incorporated different weighting factors into the position update process of ants around the antlion, who has been selected by roulette wheel selection technique. Via the applications in antenna array synthesis, EALO was demonstrated to be superior to other methods such as Taguchi Method (TM), Cat swarm optimization (CSO), ABCA, PSO and ALO. In another case, a modified ALO (MALO) [35] has been developed based on the elitism phase of classical ALO to improve exploration capability and balance between the exploration and the exploitation. The compared results pointed out that MALO has outperformed the traditional ALO and other methods in minimizing optimal generation of reactive power for transmission power grids. Another Lévy Flight based ALO (LFALO) method has been constructed in [36]. Thus, the study has replaced a uniform distributed random walk 
with random walk of the Lévy Flight distribution so as to enhance exploration. Therefore, LFALO could speed up convergence to more optimal solutions more effectively than the original ALO as tested on 27 benchmark functions. However, the method has not been compared to other methods, especially state-of-the-art methods in recent years. Another modified ALO based on Tournament selection technique (TSALO) has been proposed and applied for optimizing quadratic assignment problem [37]. The authors have stated ALO has suffered from key drawbacks that stop ALO from finding very high quality solutions such as a long run time, local optimal stagnation and premature convergence to local optimum or near global optimum. Because of these reasons, the tournament selection technique has been used instead of the roulette wheel technique and some equations in ALO have been replaced accordingly. The method has been concluded to be the best performance in comparison with other ALO variants by using a set of benchmark functions. Clearly, the performance of LFALO and TSALO have not been investigated persuasively as comparisons with other methods outside ALO variants.

\subsection{Improved Antlion Optimization Algorithm (IALO)}

As mentioned in section above, ALO has suffered from different disadvantages for converging to good solutions with fast execution. Other improved versions of ALO have tried to develop new strategies with intent to overcome such shortcomings. We agree with the authors in [37] that the roulette wheel selection technique was not appropriate for ALO to choose the most effective solutions. In addition, we also adopt comments of authors in [36] that new solution generation function of ALO needs to be improved more effectively. Thus, in the paper we suggest modifying the two pointed shortcomings of ALO. In the first modification, the roulette wheel technique is removed and replaced with a new technique. The new technique helps the ALO to classify antlions into two groups consisting of the potential traps and the non-potential trap, and then takes each group into the second modified phase. In the second modification, some novel equations with breakthrough steps will be used respectively for each group to enhance ability of the diverse exploration and the thorough exploitation in multi-solution spaces. The modifications are explained as follows.

\subsection{Two Proposed Modifications}

\subsubsection{The First Modification}

The roulette wheel is one of the reasons causing the undesired results as well as ineffectively premature convergence. The roulette wheel technique only concentrates on collecting superiority solutions rather than selecting worse solutions in a cluster. Basically, the performance of the technique is truly effective when considered in the small-scale problems. Thus, for large-scale problems such as the ORPD problem with complicated equality and inequality constraints by the presence of generators and other electric components in power systems, such a technique would not be reliable. Therefore, a new selection technique will be used instead of the roulette wheel technique to classify all solutions into potential and non-potential ones. The procedure is implemented based on two following factors:

$$
\begin{gathered}
I E P_{s}=\frac{F i t_{s}}{\text { Fit }_{\text {best }}} \\
M E P=\frac{F i t_{\text {avr }}}{\text { Fit }_{\text {best }}}
\end{gathered}
$$

where Fit $t_{a v r}$ is the mean fitness of all current solutions and obtained by:

$$
\text { Fit }{ }_{a v r}=\frac{\sum_{1}^{N_{p}} F i t_{s}}{N_{p}}
$$


Thanks to the use of $I E P_{s}$ and $M E P$, all solutions are separated into potential group and non-potential group as shown in Figure 2. The solutions with $I E P_{s}$ below MEP line are arranged in potential group while others with $I E P_{S}$ above $M E P$ line are grouped in non-potential solutions.

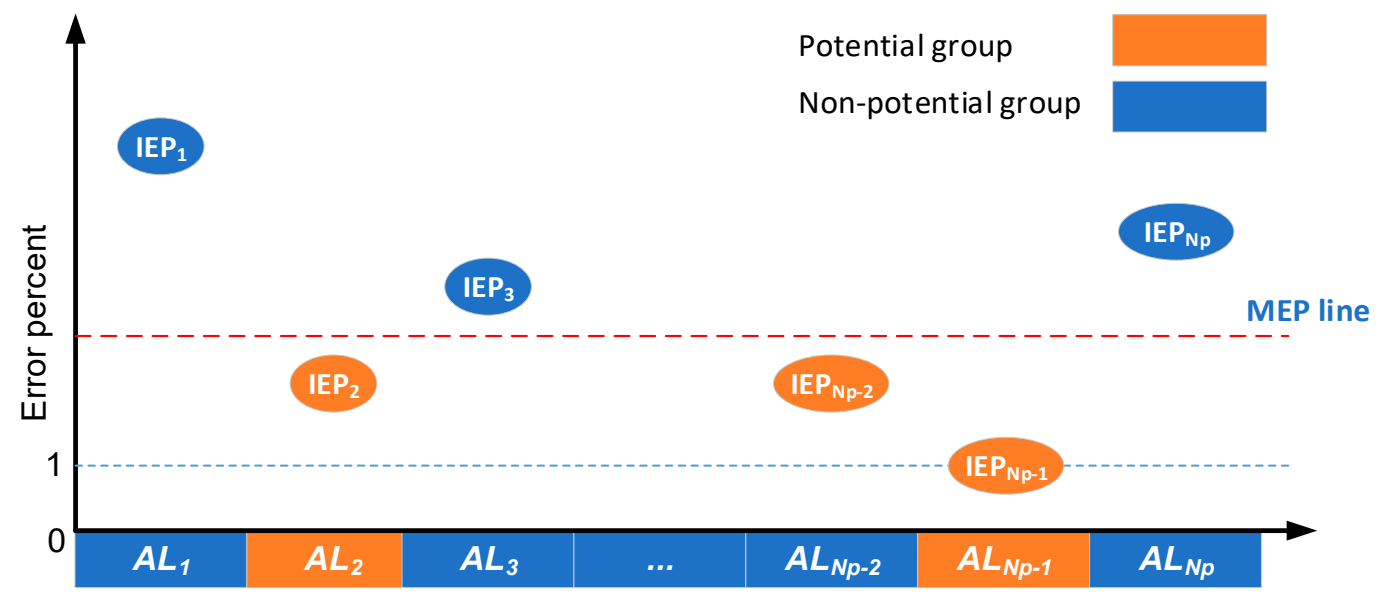

Number of Antlions

Figure 2. The procedure of classifying antlions.

\subsubsection{The Second Modification}

After the first modification, each solution in the potential group is used to determine the ants' position corresponding to the particular traps. The new position of the sth ant is determined by:

$$
A n t_{s}=A L_{s}+\left(\frac{R W_{s}^{I T}-R W_{s, \min }}{R W_{s, \max }-R W_{s, \min }}\right) \times \Delta
$$

where $\Delta$ is the breakthrough jumping step of the sth antlion and obtained based on the formula below:

$$
\Delta= \begin{cases}\left(A L_{r_{1}}-A L_{r_{2}}\right) & \text { if } \frac{C_{0} I T}{C o_{\max }} \leq 0.15 \\
\left(\begin{array}{c}
A L_{r_{1}}-A L_{r_{2}}+A L_{r_{3}}-A L_{r_{4}} \\
+A L_{r_{5}}-A L_{r_{6}}
\end{array}\right) & \text { if } \frac{C_{0} o^{I T}}{C_{\max }}>0.3 \\
\left(A L_{r_{1}}-A L_{r_{2}}+A L_{r_{3}}-A L_{r_{4}}\right) & \text { else }\end{cases}
$$

where $\mathrm{Co}^{I T}$ is an integer number obtained by comparing the deviation of two solutions' fitness function and a predetermined tolerance, $T o l=0.01$ at the ITth iteration and $C o_{\max }$ is the highest value of $C o^{I T}$ if comparison conditions are always satisfied. $C o^{I T}$ can be calculated by using Algorithm 1, while $C o_{\max }$ can be calculated by using Equation (30):

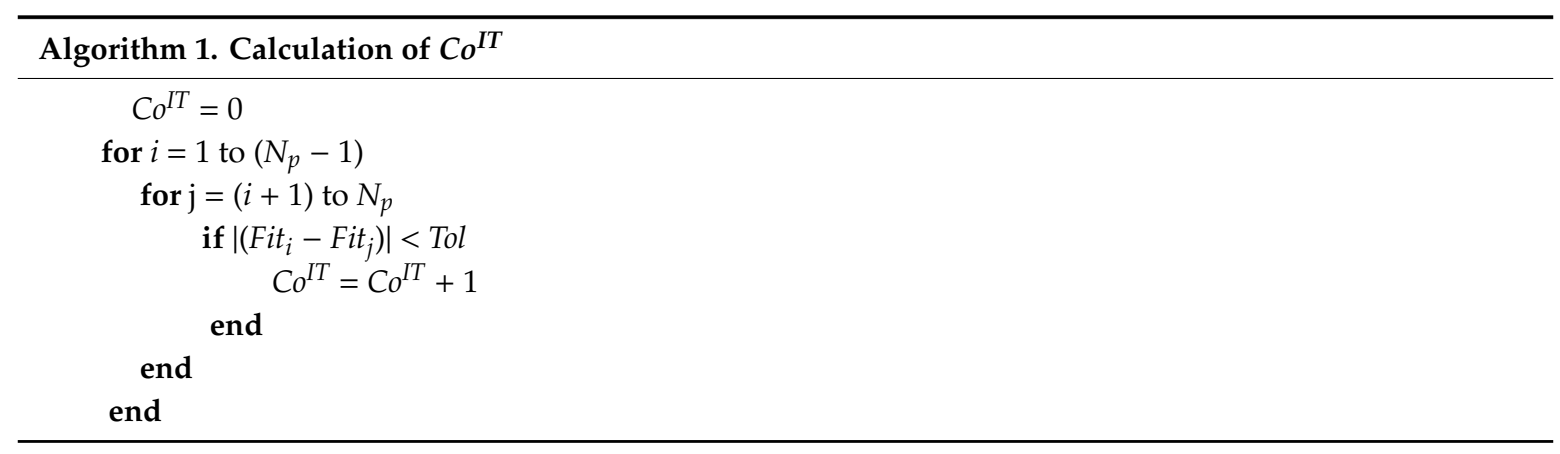

$$
C o_{\max }=\frac{N_{p} \times\left(N_{p}-1\right)}{2}
$$


In Algorithm 1 and Equation (30), $C o^{I T}$ is not fixed in the whole search process over the maximum number of iterations, while $\mathrm{Co}_{\max }$ is a constant not depending on any factors.

The non-potential antlions move to new positions with a distance nearby the best antlion:

$$
A n t_{s}=A L_{b e s t}+\alpha \times\left(A L_{r_{7}}-A L_{s}\right) \times r n_{S}
$$

where $r n_{s}$ is a random number of the $s t h$ solution and randomly produced in the range between 0 and 1 ; and $\alpha$ is Lévy factor and determined as follows [38,39]:

$$
\begin{gathered}
\alpha=v \times \frac{\theta_{h}(\omega)}{\theta_{m}(\omega)} \\
v=\frac{\operatorname{rand}_{h}}{\left(\operatorname{rand}_{m}\right)^{1 / \omega}}
\end{gathered}
$$

where $\mathrm{rand}_{h}$ and $\mathrm{rand}_{m}$ are two randomly distributed numbers with standard deviation $\theta_{h}(\omega)$ and $\theta_{m}(\omega)$ calculated by:

$$
\begin{gathered}
\theta_{h}(\omega)=\left[\frac{\Gamma(1+\omega) \times \sin (\pi \omega / 2)}{\Gamma\left(\frac{1+\omega}{2}\right) \times \omega \times 2^{(\omega-1) / 2}}\right] \\
\theta_{m}(\omega)=1
\end{gathered}
$$

where $\omega$ is the distribution factor $(0.3 \leq \omega \leq 1.99)$ and $\Gamma$ is a standard gamma function.

The execution steps of IALO are summarized in Algorithm 2.

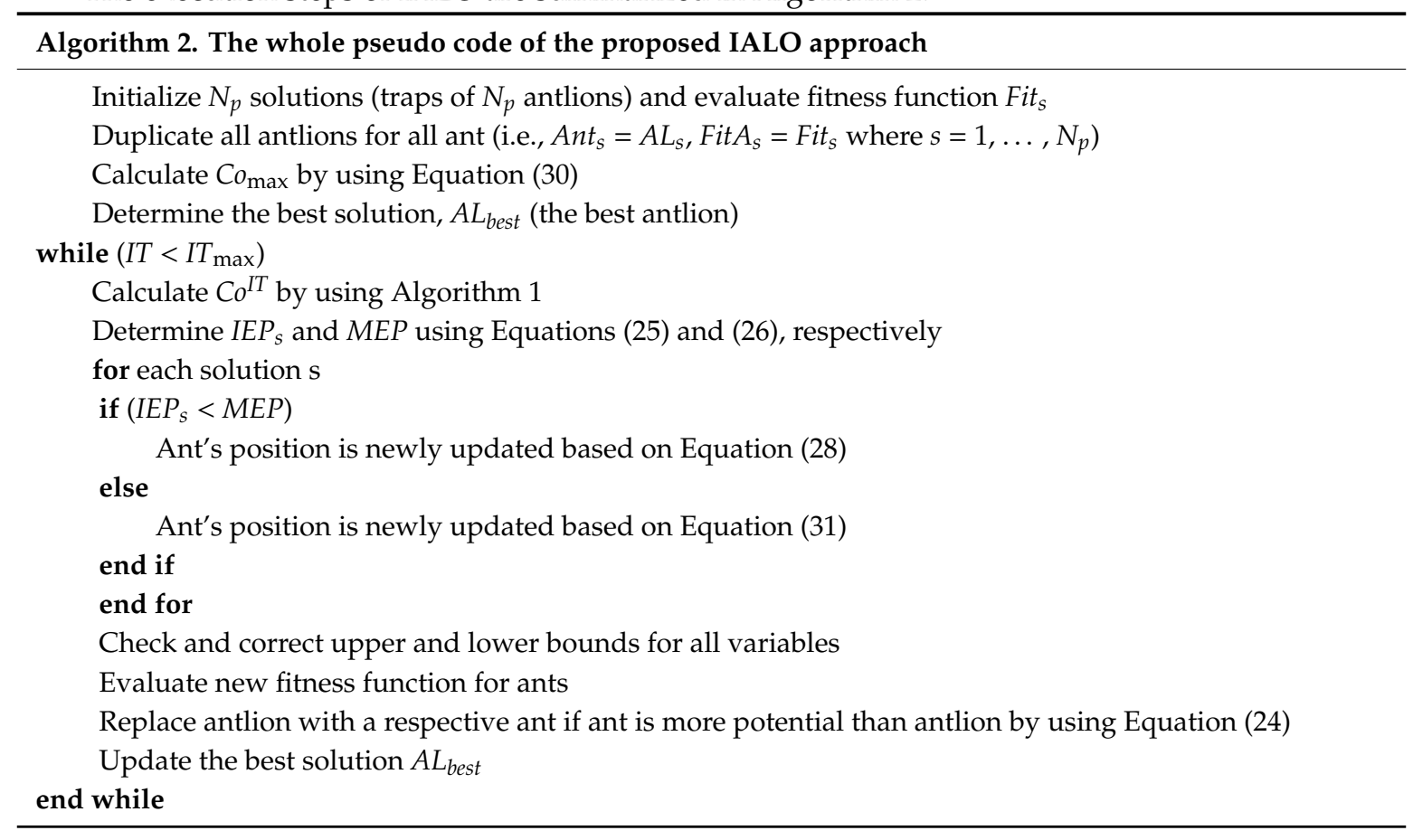

\section{Using the Proposed IALO Method for ORPD Problem}

\subsection{Selection of Control Variables for Each Solution and Generation of Initial Population}

In the proposed method, the position of each ant as well as each antlion contains control variables of the ORPD problem. Normally, the selection of such variables is one of the most important techniques for satisfying all constraints of optimization problem and finding solutions with high quality. The task is very important for the ORPD problem but there is a difference between the ORPD problem and other ones since the selected control variables must be input parameters of the Matpower program as shown 
in Section 2.3. If we set different variables to input data of the Matpower program, ORPD problem cannot be solved successfully. Thus, ALs will be formulated as follows:

$$
A L_{s}=\left\{V o l_{G 1, s}, \ldots, V_{G N_{G}, s}, T_{1, s}, \ldots, T_{N_{T}, s}, R P_{C 1, s}, \ldots, R P_{C N_{C}, s}\right\}^{T}
$$

where the position of $A L s$ must be within lower limit $A L_{\min }$ and upper limit $A L_{\max }$, which are constructed by:

$$
\begin{aligned}
A L_{\min } & =\left\{V o l_{G 1, \min }, \ldots, V_{G N_{G}, \min }, T_{1, \min }, \ldots, T_{N_{T}, \min }, R P_{C 1, \min }, \ldots, R P_{C N_{C}, \min }\right\}^{T} \\
A L_{\max } & =\left\{V o l_{G 1, \max }, \ldots, V_{G N_{G}, \max }, T_{1, \max }, \ldots, T_{N_{T}, \max }, R P_{C 1, \max }, \ldots, R P_{C N_{C}, \max }\right\}^{T}
\end{aligned}
$$

As a result, the initial population can be generated by the following rule:

$$
A L_{s}=A L_{\min }+\delta \times\left(A L_{\max }-A L_{\min }\right)
$$

\subsection{Calculate Fitness Function}

Fitness function is employed to evaluate effectiveness of solutions. Thus, the function must reflect the quality of objective function and the violation of constraints of dependent variables [40]. ORPD has three single objective functions as shown in Section 2 while the violation of constraints can be measured by checking and penalizing violation of dependent variables. In the first step, all control variables in each solution are assigned to input data of Matpower program and then the program is run for obtaining dependent variables consisting of the voltage of each load $V o l_{L k, s}$, the apparent power of each transmission branch $S_{b, s}$ and the reactive power of each generator $R P_{G k, s}$. In the second step, the three dependent variables are verified and penalized if they violate either the lower bound or upper bound. The second step can be accomplished by using the following equations:

$$
\begin{gathered}
\Delta R P_{G k, s}= \begin{cases}R P_{G k, s}-R P_{G k, \max } & \text { if } R P_{G k, s}>R P_{G k, \max } \\
0 & \text { if } R P_{G k, \min } \leq R P_{G k, s} \leq R P_{G k, \max } \\
R P_{G k, \min }-R P_{G k, s} & \text { if } R P_{G k, s}<R P_{G k, \min }\end{cases} \\
\Delta V o l_{L k, s}= \begin{cases}V o l_{L k, s}-V o l_{L, \max } & \text { if } V o l_{L k, s}>V o l_{L, \max } \\
0 & \text { if } V o l_{L, \min } \leq V o l_{L k, s} \leq V o l_{L, \max } \\
V o l_{L, \text { min }}-V o l_{L k, s} & \text { else } V o l_{L, \min }>V o l_{L k, s}\end{cases} \\
\Delta S_{b, s}= \begin{cases}0 & \text { if } S_{b, s} \leq S_{b \max } \\
S_{b, s}-S_{b, \max } & \text { if } S_{b, s}>S_{b, \max }\end{cases}
\end{gathered}
$$

Finally, fitness function Fit $t_{s}$ for evaluating effectiveness of solution $s$ is established with the following model:

$$
\text { Fit }_{s}=\text { objective }_{s}+K_{1}\left(\sum_{k=1}^{N_{G}} \Delta R P_{G k, s}\right)+K_{2}\left(\sum_{k=1}^{N_{L}} \Delta V o l_{L k, s}\right)+K_{3}\left(\sum_{b=1}^{N_{\text {branch }}} \Delta S_{b, s}\right)
$$

\subsection{Processes of Newly Updated Solutions}

The proposed IALO method only updates new solutions one time. However, the updating procedure is divided to two phases as mentioned in Section 3. In the first phase, solutions in potential group are newly updated through Equation (28). In another phase, the remaining antlions in non-potential group are newly updated via Equation (31). 


\subsection{Handling Violation of Control Variables}

After producing new solutions, all variables in such solutions will be compared to upper and lower bound. If the variables are lower than lower bound, they are assigned to lower bound. On the contrary, they are assigned to upper bound if they are higher than upper bound. The method is can be easily accomplished by using the following formulas:

$$
\begin{aligned}
& V o l_{G k, s}=\left\{\begin{array}{l}
V o l_{G k, \min } \text { if } V o l_{G k, s}<V l_{G k, \min } \\
V o l_{G, s} \text { if } V o l_{G k, \min } \leq V o l_{G k, s} \leq V o l_{G k, \max } ; k=1, \ldots, N_{G} \\
V o l_{G k, \max } \text { else }
\end{array}\right. \\
& T_{k, s}=\left\{\begin{array}{l}
T_{k, \max } \text { if } T_{k, s}>T_{k, \max } \\
T_{k, s} \text { if } T_{k, \min } \leq T_{k, s} \leq T_{k, \max } ; k=1, \ldots, N_{T} \\
T_{k, \min } \text { if else }
\end{array}\right. \\
& R P_{c k, s}=\left\{\begin{array}{l}
R P_{c k, \max } \text { if } R P_{c k, s}>R P_{c k, \max } \\
R P_{c k, s} \text { if } R P_{c k, \text { min }} \leq R P_{c k, s} \leq R P_{c k, \max } ; k=1, \ldots, N_{C} \\
R P_{c k, \text { min }} \text { else }
\end{array}\right.
\end{aligned}
$$

\subsection{Computation Termination Condition}

The performance of the proposed method is evaluated by analyzing the results from 50 trials for each study case, i.e., for each objective of each power system. Each run is not finished until the last iteration is carried out. Moreover, a study case can come to a conclusion if a predetermined number of trial runs is finished. Thus, the selection of the maximum number of iterations $I T_{\max }$ is very important for obtaining an optimal solution and to terminate the search process of the proposed method. One run can store one optimal solution and the maximum number of runs $\mathrm{No}_{\text {run }}$ can store $\mathrm{No}_{\text {run }}$ optimal solutions. In finding optimal solutions of three IEEE power system, the maximum number of iterations $I T_{\max }$ is selected depending on the dimension of each system while $\mathrm{No}_{\text {run }}$ is selected to be 50 for all study cases.

\subsection{The Entire Computation Procedure}

Finding the ORPD problem solutions can be successfully accomplished by using the following steps:

Step 1: Set values to control parameters including $N_{p}, I T_{\max }$ and $T o l$.

Step 2: Randomly produce $N_{p}$ initial solutions by using Equation (39).

Step 3: Find dependent variables $V o l_{L k, s}, S_{b, s}$ and $R P_{G k, s}$ by running the Matpower program.

Step 4: Calculate one out of three objective functions in Equations (1)-(3). Determine penalty terms as shown in Equations (40)-(42). Determine fitness function by using Equation (43). Set the solution with the best fitness to $A L_{b e s t}$. Set current iteration to $1(I T=1)$.

Step 5: Calculate $C O^{I T}$ by using Algorithm 1. Determine $I E P_{S}$ and $M E P$ using Equations (25) and (26), respectively. If $I E P_{S}<M E P$, use Equation (28) for producing new solutions. Otherwise, use Equation (31) for producing new solutions.

Step 6: Step 6: Correct all control variables by using Equations (44)-(46).

Step 7: Find dependent variables $V{ }_{L k k, s}, S_{b, s}$ and $R P_{G k, s}$ by running the Matpower program.

Step 8: Calculate one out of three objective functions in Equations (1)-(3). Determine penalty terms as shown in Equations (40)-(42). Determine fitness function by using Equation (43).

Step 9: Compare the sth new solution and the sth old solution in order to keep better one by using Equation (24).

Step 10: Set the best solution to $A L_{\text {best }}$.

Step 11: If $I T=I T_{\max }$, stop the iterative algorithm. Otherwise, set $I T=I T+1$ and go back to step 5 . 


\section{Numerical Results}

For investigating the capability of solving the ORPD problem as well as the robustness of the proposed IALO in finding high quality solutions, three different standard IEEE power systems have been used as study cases for comparisons. ALO and IALO have been executed in Matlab programming language and a PC (core i5, 2.0 Ghz, 4-Gb Ram). The information of three power systems are shown in Table 1 and the whole data are taken from [41]. The implementation of ALO and the proposed IALO methods have been accomplished by setting population size and the maximum number of iterations to 30 and 50 for the first system, 30 and 150 for the second system and 30 and 250 for the last system. For each study case, results from each method have been gathered by running 50 trials.

Table 1. The information of three standard IEEE power systems.

\begin{tabular}{ccccccc}
\hline Study Case & $\begin{array}{c}\text { No. } \\
\text { Generators }\end{array}$ & No. Loads & $\begin{array}{c}\text { No. } \\
\text { Branches }\end{array}$ & $\begin{array}{c}\text { No. } \\
\text { Compensators }\end{array}$ & $\begin{array}{c}\text { No. } \\
\text { Transformers }\end{array}$ & $\begin{array}{c}\text { No. Control } \\
\text { Variables }\end{array}$ \\
\hline IEEE 30-bus system & 6 & 24 & 41 & 9 & 4 & 19 \\
IEEE 57-bus system & 7 & 50 & 80 & 3 & 15 & 25 \\
IEEE 118-bus system & 54 & 64 & 186 & 14 & 9 & 77 \\
\hline
\end{tabular}

\subsection{Comparisons of Results from IEEE 30-Bus System}

\subsubsection{Testing the Effectiveness of Two Modifications on the Proposed Method}

In this section, we have implemented both ALO and IALO for three objectives of the first system by setting different values to iteration from 50 to 150 for ALO, while 50 iterations have been fixed for IALO. Table 2 reports obtained results. Results from the same 50 iterations can indicate that all values of IALO consisting of minimum and average of TPL, TVD and L-index are smaller than those of ALO. For TPL, ALO finds the best optimal solution with 4.6001 MW and the average of 50 optimal solutions is 4.7512; meanwhile, the results of IALO are 4.5142 and $4.5693 \mathrm{MW}$, which are, respectively, less than those of ALO by $0.086 \mathrm{MW}$ and $0.1459 \mathrm{MW}$. For a better comparison, the power loss can be converted into an improvement percentage (IP) and they are equivalent to $1.867 \%$ and $3.1 \%$. Similarly, the proposed IALO is also more robust than ALO for TVD and L-index cases since minimum and average values of the proposed method continue to be smaller. The improvement of minimum and average are $26.09 \%$ and $35.75 \%$ for TVD, and $0.56 \%$ and $4.55 \%$ for L-index, respectively. The two numbers from each objective can result in two conclusions: that the proposed IALO approach can find more optimal solutions than ALO and that its search stabilization is more effective. For further investigation of the improvement of IALO as compared to ALO, we have continued to increase the iterations to 100 and 150 for implementing ALO; however, the best optimal solutions of ALO are still worse than those of IALO obtained by setting the number of iterations to 50 . The execution time that the proposed method can find the best optimal solutions is around 4 seconds; however, it takes ALO more than 12 seconds to find lower quality solutions. Figures $3-5$ show the best convergence characteristic and the average convergence characteristic of 50 trial runs obtained by ALO and IALO in which IALO has six curves corresponding to 50 iterations, 100 iterations and 150 iterations, while IALO has two curves with 50 iterations. Clearly, the efficiency of ALO can be improved more significantly by increasing $I T_{\max }$ from 50 iterations to 100 iterations and 150 iterations; however, the best solution at the final iteration is still much worse than that of the proposed method. Thus, the proposed method can be at least three times faster than ALO. In addition, we have collected the best solutions of 50 runs obtained by the proposed method and ALO with $I T_{\max }=50$ and plotted in Figures $6-8$. The three figures have the same point that almost all runs of the proposed method have better quality than those from ALO. Consequently, it can confirm that the proposed modifications are really useful for the proposed method in solving the IEEE 30-bus system. 
Table 2. Testing performance improvement of IALO over ALO for IEEE 30-bus system.

\begin{tabular}{|c|c|c|c|c|c|}
\hline \multirow{2}{*}{ Case } & \multirow{2}{*}{$\frac{I T_{\max }}{\text { Method }}$} & \multicolumn{2}{|c|}{50} & \multirow{2}{*}{$\begin{array}{c}100 \\
\text { ALO }\end{array}$} & \multirow{2}{*}{$\begin{array}{c}150 \\
\text { ALO }\end{array}$} \\
\hline & & IALO & ALO & & \\
\hline \multirow{3}{*}{$T P L$} & Min & 4.5142 & 4.6001 & 4.572 & 4.543 \\
\hline & Aver & 4.5693 & 4.7152 & 4.66 & 4.637 \\
\hline & CPu time (s) & 3.9 & 4.3 & 8.7 & 12.3 \\
\hline \multirow{3}{*}{ TVD } & Min & 0.0881 & 0.1192 & 0.1047 & 0.094 \\
\hline & Aver & 0.1012 & 0.1575 & 0.1320 & 0.1164 \\
\hline & CPu time (s) & 3.87 & 4.1 & 8.8 & 12.6 \\
\hline \multirow{3}{*}{ L-index } & Min & 0.1246 & 0.1253 & 0.1249 & 0.1248 \\
\hline & Aver & 0.1258 & 0.1318 & 0.1287 & 0.1264 \\
\hline & CPu time (s) & 4.1 & 4.8 & 9.0 & 12.9 \\
\hline
\end{tabular}

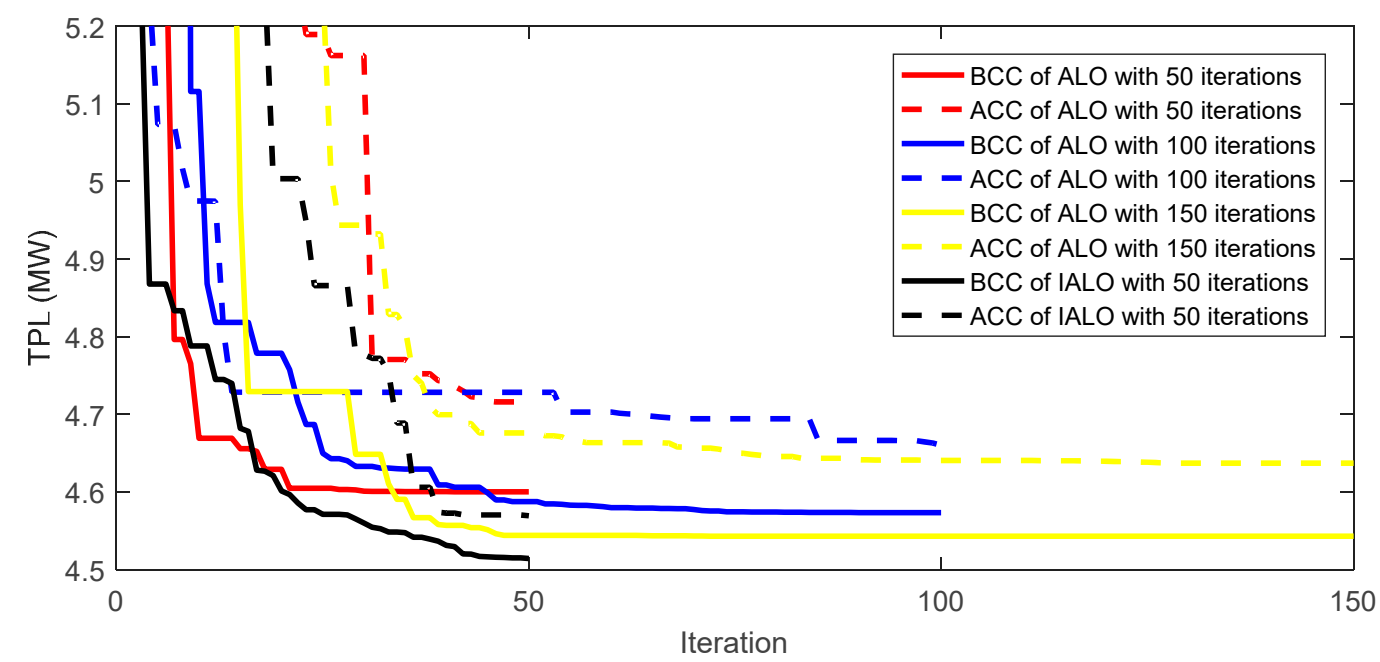

Figure 3. The best convergence characteristics (BCC) and average convergence characteristics (ACC) obtained by ALO and the proposed method for TPL objective.

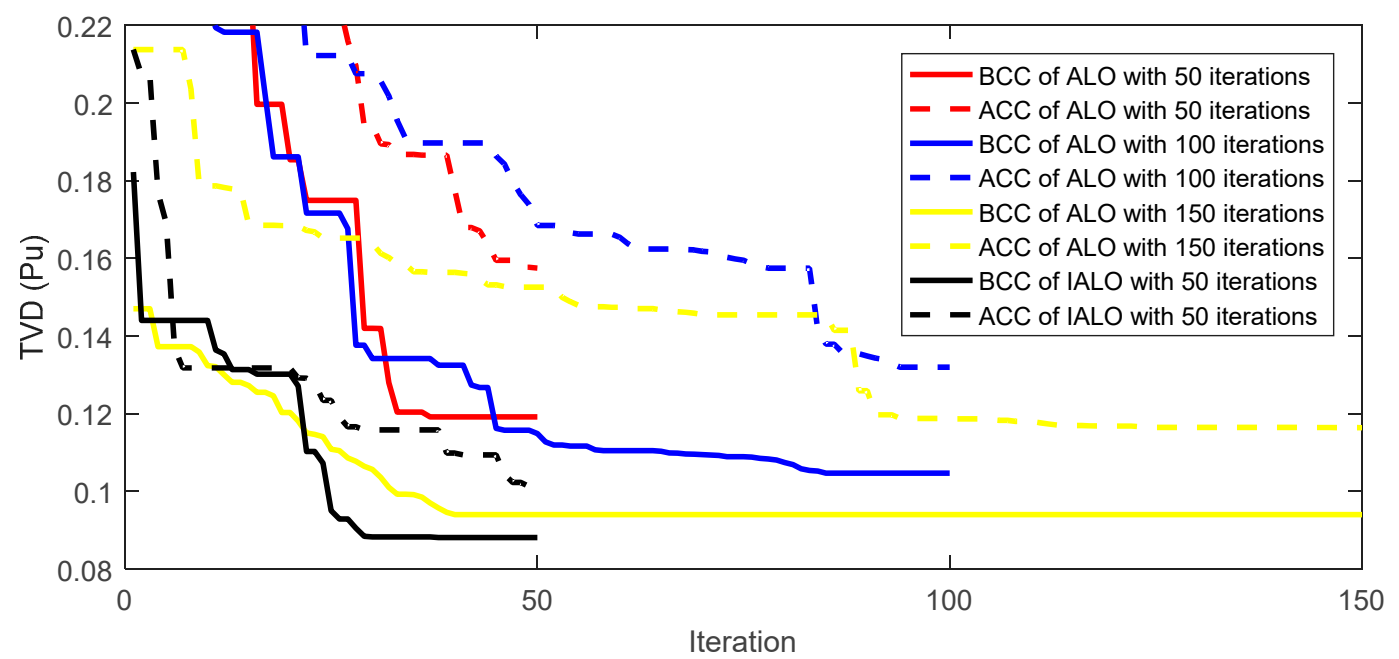

Figure 4. The best and average convergence characteristics obtained by ALO and the proposed method for TVD objective. 


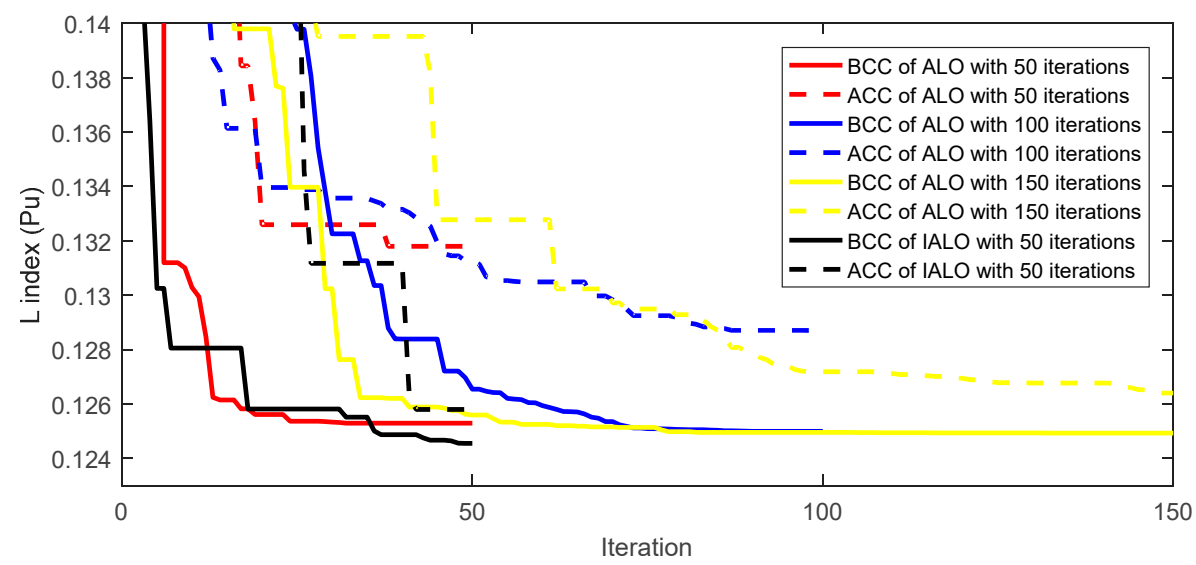

Figure 5. The best and average convergence characteristics obtained by ALO and the proposed method for L-index objective.

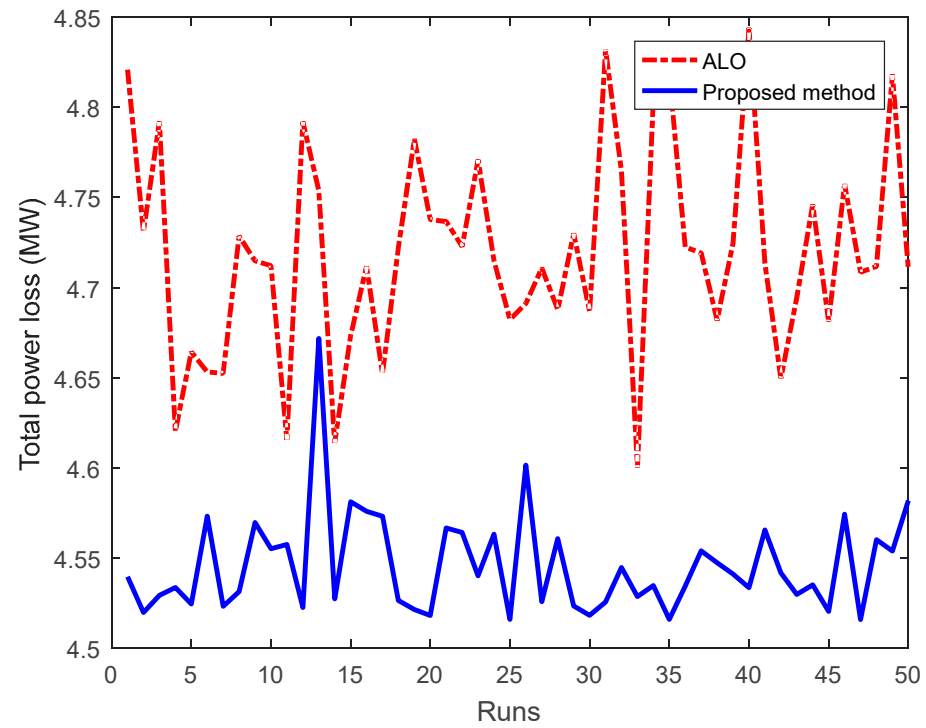

Figure 6. Total power loss of 50 runs obtained by ALO and the proposed method for IEEE 30-bus system.

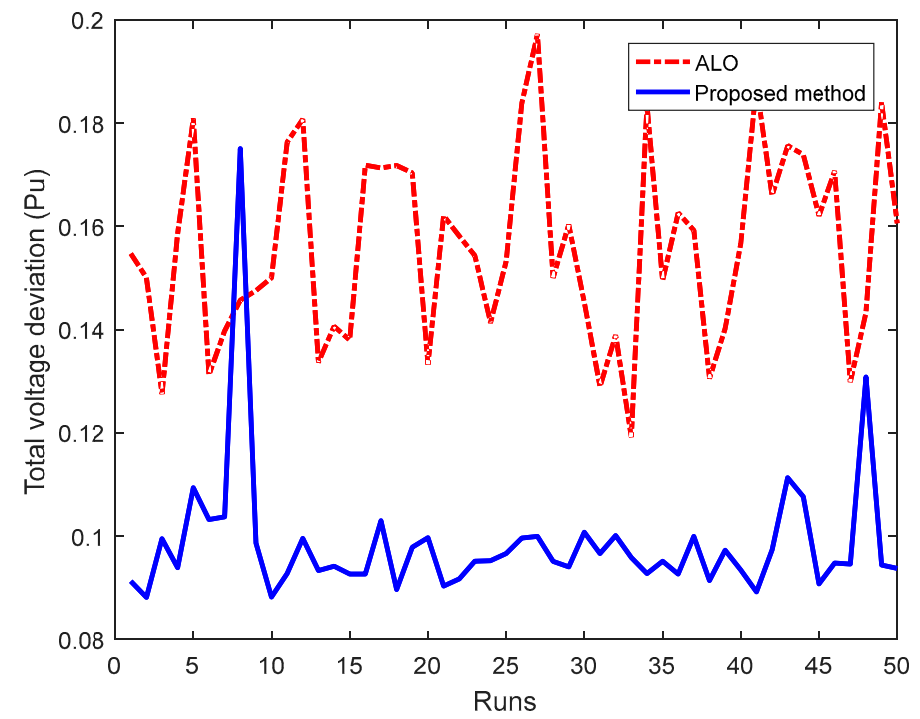

Figure 7. Total voltage deviation of 50 runs obtained by ALO and the proposed method for IEEE 30-bus system. 


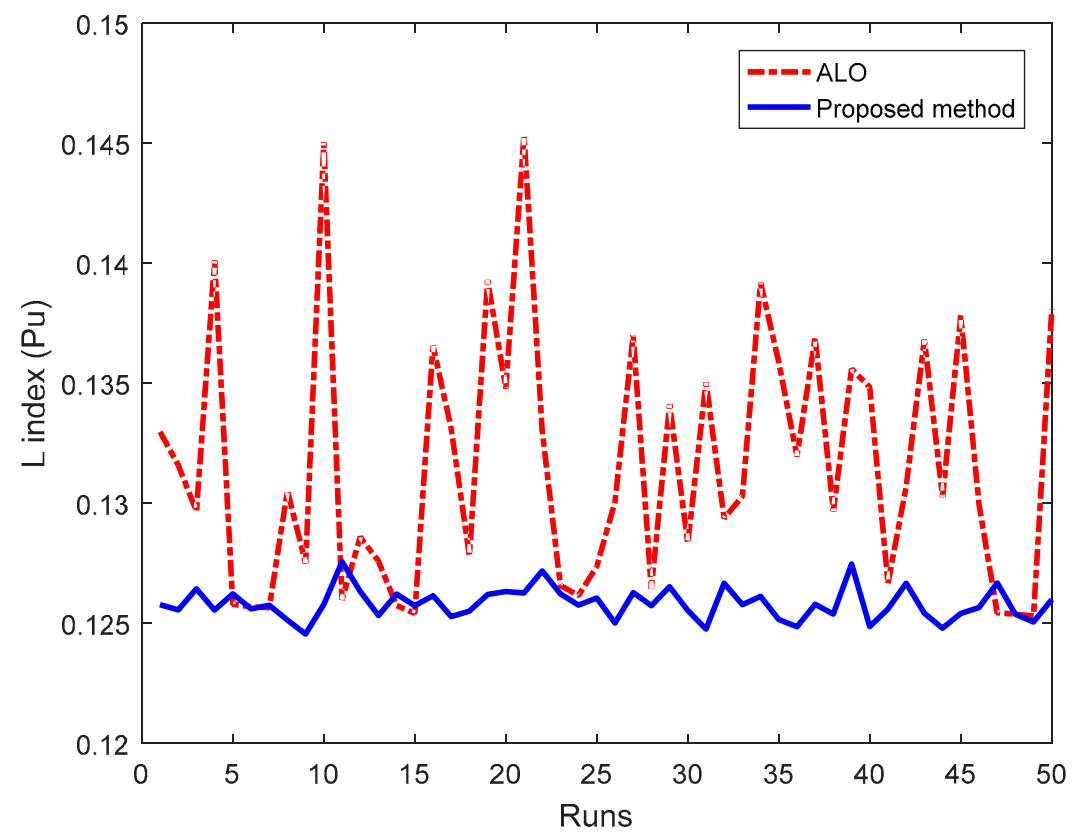

Figure 8. L-index of 50 runs obtained by ALO and the proposed method for IEEE 30-bus system.

\subsubsection{Comparing the Proposed Method with Other Existing Ones}

Result comparisons found by IALO and other methods are shown in Tables 3-5 for the TPL, TVD and L-index cases, respectively. The best and worst minima of TPL obtained by other methods in Table 3 are, respectively, 4.9408 MW and 4.51431 MW from SGA [15] and GSA [16]. Clearly, GSA [16] has approximately the same TPL with IALO, while SGA is much worse than IALO because the improvement percentage of IALO over SGA can be up to $8.63 \%$. However, it needs to compare the population size and iterations of compared methods. GSA has used 200 particles and 100 iterations corresponding to total number of newly updated solutions $\left(N_{n u s}\right)$ of 20,000 while that of IALO was only 1500. Other methods have been also run by setting much higher number of newly updated solutions, which was from 4000 to 75,000. In this regard, the outstanding search ability of IALO is understood via the fastest computation time. Execution time of IALO is under four seconds while that of other methods, which have used 4000 new solutions, is higher than seven seconds. Execution time of other remaining methods have not been reported. Thus, the IALO method is very efficient for the task of minimizing TPL of IEEE 30-bus system.

Table 3. Result comparison of total power loss for IEEE 30-bus system.

\begin{tabular}{ccccccc}
\hline Method & $\begin{array}{c}\text { The Best Power } \\
\text { Loss (MW) }\end{array}$ & $\begin{array}{c}\text { Mean Power } \\
\text { Loss (MW) }\end{array}$ & $\begin{array}{c}\text { CPU Time } \\
\text { (s) }\end{array}$ & $\boldsymbol{I T}_{\max }$ & $\boldsymbol{N}_{\boldsymbol{p}}$ & $\boldsymbol{N}_{\text {nus }}$ \\
\hline EPM [1] & 5.0159 & - & - & - & - & - \\
DE [3] & 5.011 & 5.013 & 13.647 & 200 & 30 & 6000 \\
DE [4] & 4.555 & - & - & 500 & 150 & 75,000 \\
CIDE [5] & 4.5333 & 4.5333 & - & 300 & 50 & 15,000 \\
IDE [6] & 4.5521 & - & 116 & 500 & - & - \\
AGA [7] & 4.926 & 4.952 & - & 370 & 50 & 18,500 \\
CGA [7] & 4.980 & 5.081 & - & 370 & 50 & 18,500 \\
SARCGA [8] & 4.5913 & 4.5972 & - & 300 & 36 & 10,800 \\
PGA [9] & 4.5399 & 4.5448 & - & 300 & 60 & 18,000 \\
PSO-TVIW [12] & 4.8458 & 4.8761 & 8.762 & 200 & 20 & 4000 \\
PSO-TVAC [12] & 4.8449 & 4.8702 & 8.68 & 200 & 20 & 4000 \\
SPSO-TVAC [12] & 4.5262 & 4.5564 & 9.092 & 200 & 20 & 4000 \\
PSO-CF [12] & 4.5258 & 4.5711 & 8.48 & 200 & 20 & 4000 \\
PG-PSO [12] & 4.6425 & 4.732 & 8.216 & 200 & 20 & 4000 \\
\hline
\end{tabular}


Table 3. Cont.

\begin{tabular}{|c|c|c|c|c|c|c|}
\hline Method & $\begin{array}{c}\text { The Best Power } \\
\text { Loss (MW) }\end{array}$ & $\begin{array}{c}\text { Mean Power } \\
\text { Loss (MW) }\end{array}$ & $\begin{array}{l}\text { CPU Time } \\
\text { (s) }\end{array}$ & $I T_{\max }$ & $N_{p}$ & $N_{n u s}$ \\
\hline SWT-PSO [12] & 4.6578 & 4.9413 & 7.995 & 200 & 20 & 4000 \\
\hline PGSWT-PSO [12] & 4.7914 & 5.2349 & 7.912 & 200 & 20 & 4000 \\
\hline PSO-IPGS [12] & 4.5256 & 4.5508 & 7.852 & 200 & 20 & 4000 \\
\hline SGA [15] & 4.9408 & 5.0378 & - & 30,000 & - & - \\
\hline PSO [15] & 4.9239 & 4.972 & - & 30,000 & - & - \\
\hline HAS [15] & 4.9059 & 4.924 & - & 30,000 & - & - \\
\hline GSA [16] & 4.51431 & - & - & 200 & 100 & 20,000 \\
\hline QOTLBOA [17] & 4.5594 & 4.5601 & - & 100 & 50 & 10,000 \\
\hline TLBOA [17] & 4.5629 & 4.5695 & - & 100 & 50 & 10,000 \\
\hline ALO [19] & 4.59 & - & 119.3 & 100 & 40 & 4000 \\
\hline BA [19] & 4.628 & - & 129.4 & 100 & 40 & 4000 \\
\hline GWOA [19] & 4.6119 & - & 127.2 & 100 & 40 & 4000 \\
\hline ABCA [19] & 4.611 & - & 130.6 & 100 & 40 & 8000 \\
\hline MOALO [20] & 4.7633 & - & 56.1 & - & - & - \\
\hline BSO [22] & 4.6338 & - & - & 300 & 50 & 15,000 \\
\hline PSO [23] & 4.7779 & - & - & 150 & - & - \\
\hline PSO-TVAC [23] & 4.6469 & - & - & 150 & - & - \\
\hline WOA [23] & 4.5943 & - & - & 150 & - & - \\
\hline GBWCA [24] & 4.4801 & - & - & - & 50 & 50,000 \\
\hline WCA [24] & 4.5161 & - & - & - & 50 & 50,000 \\
\hline MFOM [27] & 4.5128 & & & & & \\
\hline JAYA [28] & 4.5495 & - & - & 300 & 50 & 15,000 \\
\hline MSSO [29] & 4.51445 & 4.69215 & 4.5 & 50 & 25 & 1424 \\
\hline SCA [30] & 4.9408 & 5.0378 & - & 30,000 & - & - \\
\hline ISCA [30] & 4.5399 & 4.5518 & - & - & - & - \\
\hline EJOT [31] & 4.549 & - & - & 300 & 50 & 15,000 \\
\hline ACSOSM [32] & 4.51279 & - & - & - & - & - \\
\hline IALO & 4.5142 & 4.5693 & 3.9 & 50 & 30 & 1500 \\
\hline
\end{tabular}

Table 4. Result comparison of total voltage deviation for IEEE 30-bus system.

\begin{tabular}{ccccccc}
\hline Method & $\begin{array}{c}\text { Minimum } \\
\text { Voltage } \\
\text { Deviation (pu) }\end{array}$ & $\begin{array}{c}\text { Mean Voltage } \\
\text { Deviation (pu) }\end{array}$ & $\begin{array}{c}\text { CPU Time } \\
\text { (s) }\end{array}$ & $\boldsymbol{I T}_{\max }$ & $\boldsymbol{N}_{\boldsymbol{p}}$ & $\boldsymbol{N}_{\text {nus }}$ \\
\hline DE [4] & 0.0911 & - & - & 500 & 150 & 75,000 \\
PSO-TVIW [12] & 0.1038 & 0.1597 & 12.25 & 200 & 20 & 4000 \\
PSO-TVAC [12] & 0.2064 & 0.2376 & 12.88 & 200 & 20 & 4000 \\
SPSO-TVAC [12] & 0.1354 & 0.1558 & 12.59 & 200 & 20 & 4000 \\
PSO-CF [12] & 0.1287 & 0.1557 & 12.94 & 200 & 20 & 4000 \\
PG-PSO [12] & 0.1202 & 0.144 & 12.45 & 200 & 20 & 4000 \\
SWT-PSO [12] & 0.1614 & 0.1814 & 22.57 & 200 & 20 & 4000 \\
PGSWT-PSO [12] & 0.1539 & 0.2189 & 22.32 & 200 & 20 & 4000 \\
PSO-IPGS [12] & 0.0892 & 0.1078 & 9.724 & 200 & 20 & 4000 \\
TLBOA [17] & 0.0913 & 0.0934 & - & 100 & 50 & 10,000 \\
QOTLBOA [17] & 0.0856 & 0.0872 & - & 100 & 50 & 10,000 \\
IALO & 0.0881 & 0.1012 & 3.87 & 50 & 30 & 1500 \\
\hline
\end{tabular}

For the case of minimizing TVD, IALO is also the best method in finding the optimal solution satisfying all constraints and owning the smallest TVD. The minimum TVD of IALO is $0.0881 \mathrm{pu}$, while the second best method, IPG-PSO [12], has been reported to be $0.0892 \mathrm{pu}$; the worst method, PSO-TVAC [12], has been reported to be $0.2064 \mathrm{pu}$. Accordingly, the proposed IALO approach can improve results from $1.23 \%$ to $57.32 \%$. Other comparison information, such as computation time and control parameters, also gives the same result: IALO is faster than all other methods. In fact, IALO has been implemented by using 1,500 evaluations for objective function while that of others was from 4000 to 75,000 . The setting has taken IALO 3.87 seconds while it has taken other methods from 9.724 to 22.57 seconds. As a result, we can conclude that IALO outperforms other compared methods in solving IEEE 30-bus system with a TVD objective. 
Table 5. Result comparison of L-index for IEEE 30-bus system

\begin{tabular}{ccccccc}
\hline Method & $\begin{array}{c}\text { Minimum } \\
\text { L-Index (pu) }\end{array}$ & $\begin{array}{c}\text { Mean } \\
\text { L-Index (pu) }\end{array}$ & $\begin{array}{c}\text { CPU Time } \\
\text { (s) }\end{array}$ & $\mathbf{I T}_{\max }$ & $\boldsymbol{N}_{\boldsymbol{p}}$ & $\boldsymbol{N}_{\text {nus }}$ \\
\hline DE [4] & 0.1246 & - & - & 500 & 50 & 25,000 \\
PSO-TVIW [12] & 0.1258 & 0.0008 & 14.42 & 200 & 20 & 4000 \\
PSO-TVAC [12] & 0.1499 & 0.0009 & 14.53 & 200 & 20 & 4000 \\
SPSO-TVAC [12] & 0.1271 & 0.0006 & 14.05 & 200 & 20 & 4000 \\
PSO-CF [12] & 0.1261 & 0.0008 & 14.39 & 200 & 20 & 4000 \\
PG-PSO [12] & 0.1264 & 0.0008 & 14.84 & 200 & 20 & 4000 \\
SWT-PSO [12] & 0.1488 & 0.0074 & 18.99 & 200 & 20 & 4000 \\
PGSWT-PSO [12] & 0.1394 & 0.0081 & 19.107 & 200 & 20 & 4000 \\
PSO-IPGS [12] & 0.1241 & 0.001 & 13.75 & 200 & 20 & 4000 \\
GSA [16] & 0.1161 & - & - & 200 & 100 & 20,000 \\
QOTLBOA [17] & 0.1242 & 0.0452 & - & 100 & 50 & 10,000 \\
TLBOA [17] & 0.1252 & 0.0454 & - & 100 & 50 & 10,000 \\
BA [19] & 0.1191 & - & 94.65 & 100 & 40 & 4000 \\
GWOA [19] & 0.118 & - & 104.29 & 100 & 40 & 4000 \\
ABCA [19] & 0.1161 & - & 105.04 & 100 & 40 & 8000 \\
ALO [19] & 0.1161 & - & 97.92 & 100 & 40 & 4000 \\
IALO & 0.1246 & 0.0006 & 3.9 & 50 & 30 & 1500 \\
IALO & 0.1241 & 0.0006 & 7.6 & 100 & 30 & 3000 \\
\hline
\end{tabular}

As shown in Table 5, GSA [16] and other methods [19] have obtained a better L-index than IALO and their result improvements over IALO can be higher than $7 \%$. However, it should recheck the constraint violation of the reported optimal solutions as well as recheck reported minimum L-index for exact confirmation. We have run Matpower and recalculated the L-index. The results were $0.1247 \mathrm{pu}$ for GSA and 0.1241 for ALO and ABCA. BA and GWOA in [19] have not shown optimal solutions. In spite of the outstanding point, these methods together with QOTLBOA [17] cannot be evaluated to be more effective than IALO because they have used more search time and more iterations as well as higher population. QOTLBOA [17] has produced 10,000 new solutions, and ALO and ABCA [19] have produced 8000 and 4000 new solutions but the proposed IALO has searched only 1500 solutions in process. Thus, it is unfair for the comparison. We have continued to run IALO by increasing iterations to 100 and keeping population size at 30 corresponding to 3000 objective function evaluations. The best L-index has been much better than before and equal to 0.1241, which is as good as that of QOTLBOA, ALO and ABCA. Although IALO and these methods have found the same quality solution, IALO has carried out search process much faster. IALO has used 3000 number evaluations while these methods have used 8000 and 4000 evaluations. Furthermore, execution time of IALO is under 8 seconds, but those from the others are approximately 100 seconds. Comparison with remaining methods also gives good evidences for confirming the effectiveness and robustness of IALO. The method can improve results from $0.95 \%$ to $16.88 \%$ and its execution time is also faster two times. Consequently, the proposed method is very efficient for the IEEE 30-bus system considering L-index objective.

Optimal solutions obtained by the proposed method for the system are shown in Table A1, Appendix A.

\subsection{Comparisons of Results from IEEE 57-Bus System}

In this section, the proposed IALO has been compared to ALO and other existing methods for evaluating performance of solving the IEEE 57-bus system. Result comparison for total power losses and total voltage deviation are, respectively, shown in Tables 6 and 7.

Comparison with ALO shown in the two tables see that the proposed method can find more optimal solutions for the two cases in which the best TPL and TVD values of the proposed method are 22.2539 MW and 0.5568 pu while those from ALO are 22.8884 MW and $0.6666 \mathrm{pu}$. The two values can support to calculate improvement percentage and the proposed method can improve the best optimal 
solution up to $2.77 \%$ for TPL and $16.47 \%$ for TVD. The average of TPL and TVD as well as all values from fifty runs shown in Figures 9 and 10 also demonstrate the superiority of the proposed method over ALO. The proposed method could find many solutions with the same or approximate TPL and TVD of the best solution, while ALO could not find solutions nearby the best solutions. Thus, it can conclude that the proposed modifications on IALO are very efficient for solving IEEE 57-bus system of ORPD problem.

For comparison with other existing methods, it can be seen that MOGWA [25] has shown the best TPL but the validation of the method cannot be checked because there was no solution reported in [25]. With respect to the comparison to other remaining methods, the proposed method also demonstrates its potential search persuasively, since its most optimal solution for TPL objective can reduce TPL from over $4 \%$ to over $13 \%$. For the TVD objective, the proposed method also reduces the total power losses up to over $16 \%$. Furthermore, the proposed method is always faster than other ones for the two cases. As compared total number of newly updated solutions or the number of fitness evaluations and computational time, the proposed method is always superior to all methods. In fact, IALO has employed 5000 new solutions and execution time was about 20 seconds; meanwhile, other ones have employed from 9000 to 200,000 for TPL objective corresponding to execution time from about 300 seconds to 1450 seconds, and from 10,000 to 100,000 for TVD objective corresponding to execution time of about 400 seconds. Thus, it can be concluded that the proposed method is very efficient for solving the system.

Optimal solutions obtained by the proposed method for the system are shown in Table A2, Appendix A.

Table 6. Result comparison of total power loss for the IEEE 57-bus system.

\begin{tabular}{ccccccc}
\hline Method & $\begin{array}{c}\text { Minimum Power } \\
\text { Loss (MW) }\end{array}$ & $\begin{array}{c}\text { Mean Power } \\
\text { Loss (MW) }\end{array}$ & $\begin{array}{c}\text { CPU Time } \\
\text { (s) }\end{array}$ & $\mathbf{I T}_{\text {max }}$ & $\boldsymbol{N}_{\boldsymbol{p}}$ & $\boldsymbol{N}_{\text {uus }}$ \\
\hline DE [3] & 25.0475 & 25.1112 & 35.654 & 190 & 30 & 6000 \\
PGA [9] & 23.836 & 4.5448 & 34.4150 & 300 & 60 & 18,000 \\
PSO-ALC [11] & 23.39 & 23.41 & 300.78 & 500 & 60 & 30,000 \\
PSO [13] & 24.7742 & - & 927 & 500 & 190 & 100,000 \\
ICA [13] & 24.1607 & - & 1018 & 500 & 190 & 100,000 \\
PSO-ICA [13] & 24.1386 & - & 1450 & 500 & 190 & 100,000 \\
SGA [15] & 25.64 & 26.8378 & - & - & - & - \\
PSO [15] & 25.03 & 26.4742 & - & - & - & - \\
HAS [15] & 24.9059 & 26.9653 & - & - & - & - \\
GSA [16] & 23.46 & - & 321.4872 & 150 & 90 & \\
KHA [18] & 23.41 & - & 303.15 & 100 & 50 & 10,000 \\
CKHA [18] & 23.38 & - & 301.12 & 100 & 50 & 10,000 \\
MOALO [20] & 26.593 & - & 531.07 & - & - & - \\
DSA [21] & 23.35 & - & - & 1900 & 100 & 190,000 \\
BSO [22] & 24.3744 & - & - & 300 & 50 & 15,000 \\
WCA [24] & 24.82 & - & - & - & - & - \\
GBWCA [24] & 23.27 & - & - & - & - & - \\
MOGWA [25] & 23.71544 & - & - & 100 & 30 & 6000 \\
MOGWA [25] & 21.171 & - & - & 100 & 30 & 6000 \\
GSA [26] & 24.4922 & - & - & - & - & - \\
PSO [26] & 24.3826 & - & - & - & - & - \\
CSA [26] & 24.2619 & - & - & - & - & - \\
MCBOA [26] & 23.6943 & - & - & - & - & - \\
BA [27] & 24.9254 & - & - & 300 & 30 & 9000 \\
FPA [27] & 24.8419 & - & - & 300 & 30 & 9000 \\
MFOM [27] & 24.25293 & - & - & 300 & 30 & 9000 \\
ALO & 22.8884 & 23.5584 & 20.40 & 200 & 25 & 5000 \\
IALO & 22.2539 & 23.54293 & 14.75 & 200 & 25 & 5000 \\
\hline
\end{tabular}


Table 7. Result comparison of total voltage deviation for the IEEE 57-bus system.

\begin{tabular}{ccccccc}
\hline Method & $\begin{array}{c}\text { Minimum Voltage } \\
\text { Deviation (pu) }\end{array}$ & $\begin{array}{c}\text { Mean Voltage } \\
\text { Deviation (pu) }\end{array}$ & $\begin{array}{c}\text { CPU Time } \\
\text { (s) }\end{array}$ & $\boldsymbol{I T}_{\max }$ & $\boldsymbol{N}_{\boldsymbol{p}}$ & $\boldsymbol{N}_{\boldsymbol{n u s}}$ \\
\hline PSO-ALC [11] & 0.6634 & 0.6636 & 400.39 & 500 & 60 & 30,000 \\
KHA [18] & 0.6605 & - & 398.49 & 100 & 50 & 10,000 \\
CKHA [18] & 0.6484 & - & 395.11 & 100 & 50 & 10,000 \\
DSA [21] & 0.6589 & - & - & 2000 & 100 & 100,000 \\
WCA [24] & 0.6631 & - & - & 1000 & 50 & 50,000 \\
GBWCA [24] & 0.6501 & 0.7534 & 19.53 & 200 & 25 & 5000 \\
ALO & 0.6666 & 0.5977 & 14.93 & 200 & 25 & 5000 \\
IALO & 0.5568 & & & & \\
\hline
\end{tabular}

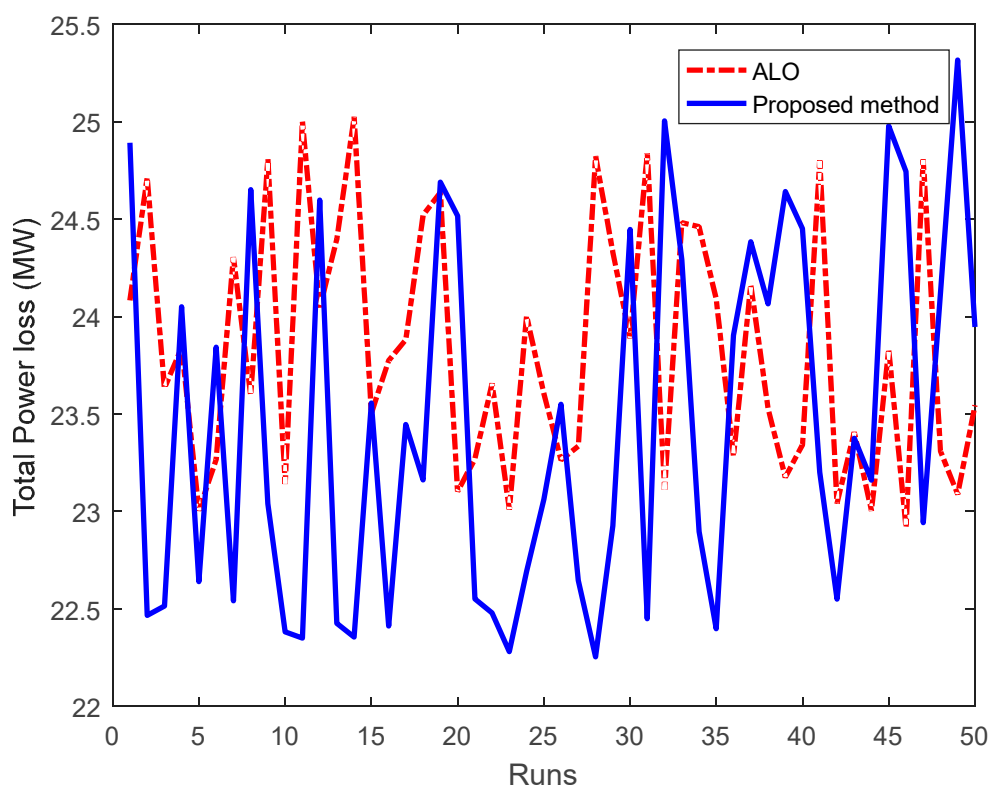

Figure 9. Total power loss of 50 runs obtained by ALO and the proposed method for IEEE 57-bus system.

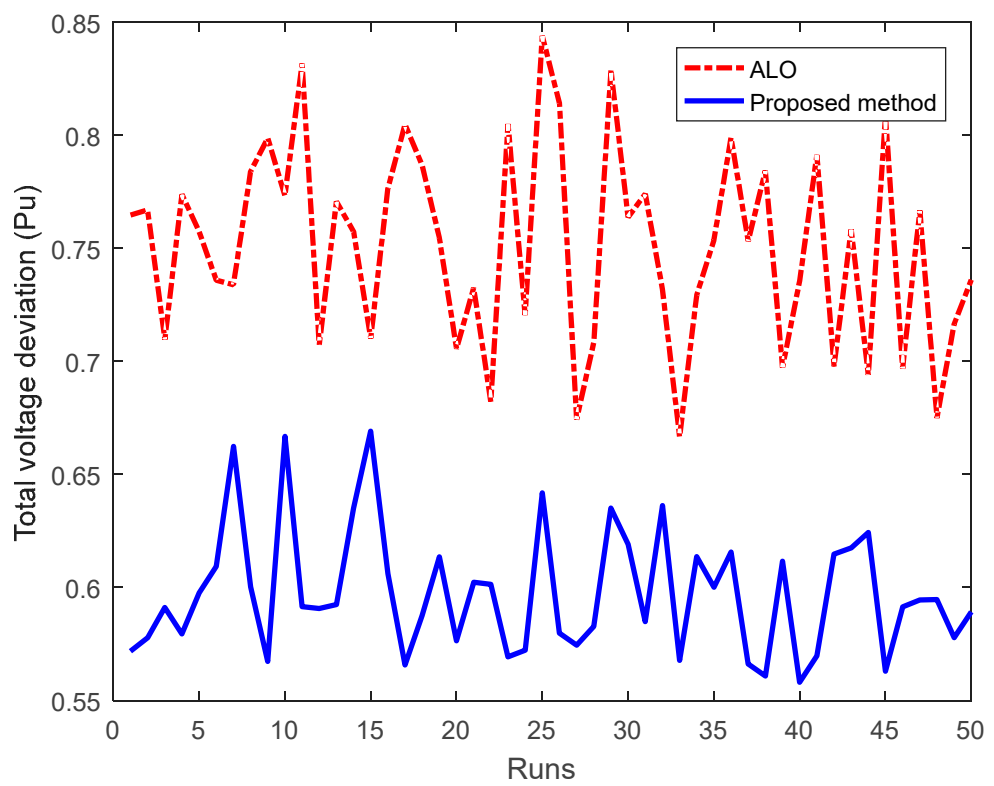

Figure 10. Total voltage deviation of 50 runs obtained by ALO and the proposed method for IEEE 57-bus system. 


\subsection{Result Comparison for IEEE 118-Bus System}

In this section, the efficiency of the proposed method has been tested by comparing optimal solutions of IEEE 118-bus system with those of ALO and other existing methods.

Similar to comparison cases above, the proposed method is more effective than ALO for three cases of IEEE 118-bus system in terms of the best optimal solutions, the stabilization of solution search process and convergence speed shown in Tables $8-10$, respectively. The best TPL, TVD and L-index of the proposed method are, respectively, $114.795 \mathrm{MW}, 0.1663 \mathrm{pu}$ and $0.0606 \mathrm{pu}$, while those of ALO are, respectively, $116.86 \mathrm{MW}, 0.2681 \mathrm{pu}$ and $0.0609 \mathrm{pu}$. The proposed method could improve results up to $1.764 \%, 37.958 \%$ and $0.25 \%$ for TPL, TVD and L-index cases, respectively. Furthermore, average values from the proposed method are always smaller than those of ALO. They are, respectively, 117.299 MW, $0.193 \mathrm{pu}$ and $0.0608 \mathrm{pu}$, but those of ALO are much higher and equal to $119.712 \mathrm{MW}, 0.379 \mathrm{pu}$ and $0.0612 \mathrm{pu}$. Clearly, the proposed method is more stable than ALO in finding 50 optimal solutions for each case of IEEE 118-bus system. As a result, it can be stated that the proposed IALO should be employed for solving IEEE 118-bus system and ALO should be replaced with the proposed method in dealing with the IEEE 118-bus power system.

As compared to the proposed IALO method with other ones, the proposed method seems not to be the strongest optimization tool for TPL, TVD and L-index cases since SARCGA [8] and QOTLBOA [17] for TPL case, PG-PSO [12], SWT-PSO [12] and IPG-PSO [12] for TVD case, and SWT-PSO [12], PGSWT-PSO [12] and PSO-IPGS [12] for L-index case have reported better results. However, the validation of optimal solutions from these more superior methods should be confirmed. SARCGA has not reported solutions for TPL case, while QOTLBOA [17] has reported optimal solution and its validation was confirmed to be true. However, QOTLBOA has employed higher number of newly updated solutions, 10,000 solutions for finding the best solution while that of the proposed method was 7500 solutions. The study [12] has reported solutions for IPG-PSO only but for other ones. The verification of solutions reported for IPG-PSO can be confirmed that solutions for TPL and TVD cases are true, but the solution for the L-index exceeds upper bound of load bus voltage. Many load buses have voltage higher than 1.05 and less than 1.1. Clearly, IPG-PSO can find better solutions due to the use of higher value for the upper bound. Thus, for comparing with the IPG-PSO method, we have re-implemented the proposed IALO method by setting upper bound of load bus voltage to $1.1 \mathrm{pu}$ and L-index has been reported in bold value, which is 0.0568 pu equaling to that of IPG-PSO. Thus, the comparison with IPG-PSO is that the proposed method has reached less TPL, higher TVD and the same L-index but the proposed IALO method has employed smaller number of newly updated solutions and spent less computation time than IPG-PSO. Comparing to other remaining methods can show outstanding performance of the proposed method once the improvement of minimum TPL, TVD and L-index can be from $0.23 \%$ to $13.03 \%$ for TPL optimization case, from $7.643 \%$ to $92.561 \%$ for TVD optimization case and from $0.086 \%$ to $56.306 \%$ for L-index optimization case. The comparison of convergence speed also has the same manner since the proposed method has used a smaller number of newly updated solutions than that of approximately all methods.

All in all, the proposed method is concluded to be much more effective than standard ALO method and it is also a very effective optimization tool in solving the IEEE 118-bus power system of ORPD problem as compared to other compared methods.

Optimal solutions obtained by the proposed method for the system are shown in Tables A3-A5 in the Appendix A. 
Table 8. Result comparison of total power loss for IEEE 118-bus system.

\begin{tabular}{ccccccc}
\hline Method & $\begin{array}{c}\text { Minimum Power } \\
\text { Loss (MW) }\end{array}$ & $\begin{array}{c}\text { Mean Power } \\
\text { Loss (MW) }\end{array}$ & $\begin{array}{c}\text { CPU Time } \\
\text { (s) }\end{array}$ & $\mathbf{I T}_{\max }$ & $\boldsymbol{N}_{\boldsymbol{p}}$ & $\boldsymbol{N}_{\text {nus }}$ \\
\hline MHEPM [2] & 115.80 & - & - & 100 & 20 & 2000 \\
DE [3] & 129.579 & - & - & - & - & - \\
SARCGA [8] & 113.12 & 113.968 & - & 300 & 15 & 9000 \\
HEP [8] & 115.58 & 115.8 & - & 300 & 15 & 4500 \\
PSO-TVIW [12] & 115.8976 & 118.2344 & 109.645 & 190 & 40 & 8000 \\
PSO-TVAC [12] & 124.3335 & 129.7494 & 96.32 & 190 & 40 & 8000 \\
SPSO-TVAC [12] & 115.1926 & 117.3553 & 96.45 & 190 & 40 & 8000 \\
PSO-CF [12] & 115.6469 & 115.9863 & 95.86 & 190 & 40 & 8000 \\
PG-PSO [12] & 115.6075 & 119.3968 & 96.11 & 190 & 40 & 8000 \\
SWT-PSO [12] & 124.1476 & 129.371 & 91.58 & 190 & 40 & 8000 \\
PGSWTPSO [12] & 119.427 & 122.781 & 95.17 & 190 & 40 & 8000 \\
PSO-IPGS [12] & 115.06 & 115.462 & 91.07 & 190 & 40 & 8000 \\
SOA [14] & 133.357 & - & - & 300 & 60 & 18,000 \\
QOTLBOA [17] & 112.2789 & 113.7693 & - & 100 & 50 & 10,000 \\
TLBOA [17] & 115.4003 & 121.3902 & - & 100 & 50 & 10,000 \\
MSSO [29] & 114.5297 & 115.651 & 41.6 & 150 & 40 & 7190 \\
ALO & 116.86 & 119.712 & 50.71 & 250 & 30 & 7500 \\
IALO & 114.795 & 117.299 & 39.59 & 250 & 30 & 7500 \\
\hline
\end{tabular}

Table 9. Result comparison of total voltage deviation for IEEE 118-bus system.

\begin{tabular}{ccccccc}
\hline Method & $\begin{array}{c}\text { Minimum Voltage } \\
\text { Deviation (pu) }\end{array}$ & $\begin{array}{c}\text { Mean Voltage } \\
\text { Deviation (pu) }\end{array}$ & $\begin{array}{c}\text { CPU Time } \\
\text { (s) }\end{array}$ & $I_{\text {max }}$ & $\boldsymbol{N}_{\boldsymbol{p}}$ & $\boldsymbol{N}_{\text {nus }}$ \\
\hline PSO-TVIW [12] & 0.1935 & 0.2291 & 78.49 & 200 & 40 & 8000 \\
PSO-TVAC [12] & 0.3921 & 0.4724 & 78.7 & 200 & 40 & 8000 \\
SPSO-TVAC [12] & 0.2074 & 0.2498 & 74.9 & 200 & 40 & 8000 \\
PSO-CF [12] & 0.1801 & 0.2143 & 78.13 & 200 & 40 & 8000 \\
PG-PSO [12] & 0.1658 & 0.2084 & 51.24 & 200 & 40 & 8000 \\
SWT-PSO [12] & 0.1658 & 0.2084 & 51.24 & 200 & 40 & 8000 \\
PGSWT-PSO [12] & 0.2355 & 0.2755 & 114.5 & 200 & 40 & 8000 \\
IPG-PSO [12] & 0.162 & 0.1923 & 47.86 & 200 & 40 & 8000 \\
QOTLBOA [17] & 0.191 & 0.2043 & - & 100 & 50 & 10,000 \\
TLBOA [17] & 0.2237 & 0.2306 & - & 100 & 50 & 10,000 \\
ALO & 0.2681 & 0.379 & 45.730 & 250 & 30 & 7500 \\
IALO & 0.1663 & 0.193 & 45.879 & 250 & 30 & 7500 \\
\hline
\end{tabular}

Table 10. Result comparison of L-index for IEEE 118-bus system

\begin{tabular}{ccccccc}
\hline Method & $\begin{array}{c}\text { Minimum } \\
\text { L-Index (pu) }\end{array}$ & $\begin{array}{c}\text { Mean } \\
\text { L-Index (pu) }\end{array}$ & $\begin{array}{c}\text { CPU Time } \\
\text { (s) }\end{array}$ & $\boldsymbol{I T}_{\max }$ & $\boldsymbol{N}_{\boldsymbol{p}}$ & $\boldsymbol{N}_{\boldsymbol{n u s}}$ \\
\hline PSO-TVIW [12] & $0.0606^{*}$ & 0.0607 & 119.66 & 200 & 40 & 8000 \\
PSO-TVAC [12] & $0.0607^{*}$ & 0.0609 & 119.22 & 200 & 40 & 8000 \\
SPSO-TVAC [12] & $0.0607^{*}$ & 0.0608 & 119.16 & 200 & 40 & 8000 \\
PSO-CF [12] & $0.0606^{*}$ & 0.0607 & 119.86 & 200 & 40 & 8000 \\
PG-PSO [12] & $0.0654^{*}$ & 0.0656 & 119.65 & 200 & 40 & 8000 \\
SWT-PSO [12] & $0.0587^{*}$ & 0.0608 & 58.45 & 200 & 40 & 8000 \\
PGSWT-PSO [12] & $0.0574^{*}$ & 0.0605 & 56.43 & 200 & 40 & 8000 \\
PSO-IPGS [12] & $0.0568^{*}$ & 0.0569 & 55.62 & 200 & 40 & 8000 \\
QOTLBOA [17] & 0.0608 & 0.0631 & - & 100 & 50 & 10,000 \\
TLBOA [17] & 0.0613 & 0.0626 & - & 100 & 50 & 10,000 \\
ALO & 0.0609 & 0.0612 & 57.379 & 250 & 30 & 7500 \\
IALO & 0.0606 & 0.0608 & 46.043 & 250 & 30 & 7500 \\
IALO & $\mathbf{0 . 0 5 6 8}$ & 0.0569 & 45.891 & 250 & 30 & 7500 \\
\hline
\end{tabular}

* Methods were run by setting lower and upper bounds of load voltage to 0.9 and $1.1 \mathrm{pu}$.

\section{Conclusions}

In this paper, the proposed IALO method has been applied for dealing with three systems of ORPD problem with 30, 57 and 118 buses. The proposed method has been proved to be much more effective than its conventional ALO method, especially for the largest scale system with 118 buses. For 
the first system with 30 buses, it has been demonstrated that the proposed method could be three time faster than ALO whereas it still found better optimal solutions. Furthermore, the improvement level of the proposed method over ALO for the IEEE 30-bus system was 1.867\%, 26.09\% and 0.56\% corresponding to TPL, TVD and L-index. For the IEEE 57-bus system, the improvement level was up to $2.77 \%$ for TPL and $16.47 \%$ for TVD. For the IEEE 118-bus system, the proposed method could improve results up to $1.764 \%, 37.958 \%$ and $0.25 \%$ for TPL, TVD and the L-index, respectively. The comparisons with other existing methods have also shown the superiority of the proposed method since it could reach optimal solutions with better quality but it used smaller number of newly updated solutions and took shorter computation time. As compared to other methods, the proposed method could improve the best optimal solution significantly for the three power systems. For the IEEE 30-bus system, the improvement level was $8.63 \%$ for TPL, $57.32 \%$ for TVD and $7 \%$ for the L-index. For the IEEE 57-bus system, the improvement level was 13\% for TPL and 16\% for TVD. For the IEEE 118-bus system, the improvement level was much higher and equal to $13.03 \%$ for TPL, $92.561 \%$ for TVD and $56.306 \%$ for the L-index. Consequently, it can be concluded that the proposed IALO should be used for the ORPD problem and it can be tried for other problems in power systems.

Author Contributions: Z.L. and Y.C. have simulated results and written important parts of the article. L.V.D. and X.Y. have selected references, formatted the whole paper, summarized results in tables and written introduction. T.T.N. has edited the whole paper.

Funding: This research was funded by the National Natural Science Foundation of China (NSFC) under project No. 51520105011.

Conflicts of Interest: The authors declare no conflict of interest.

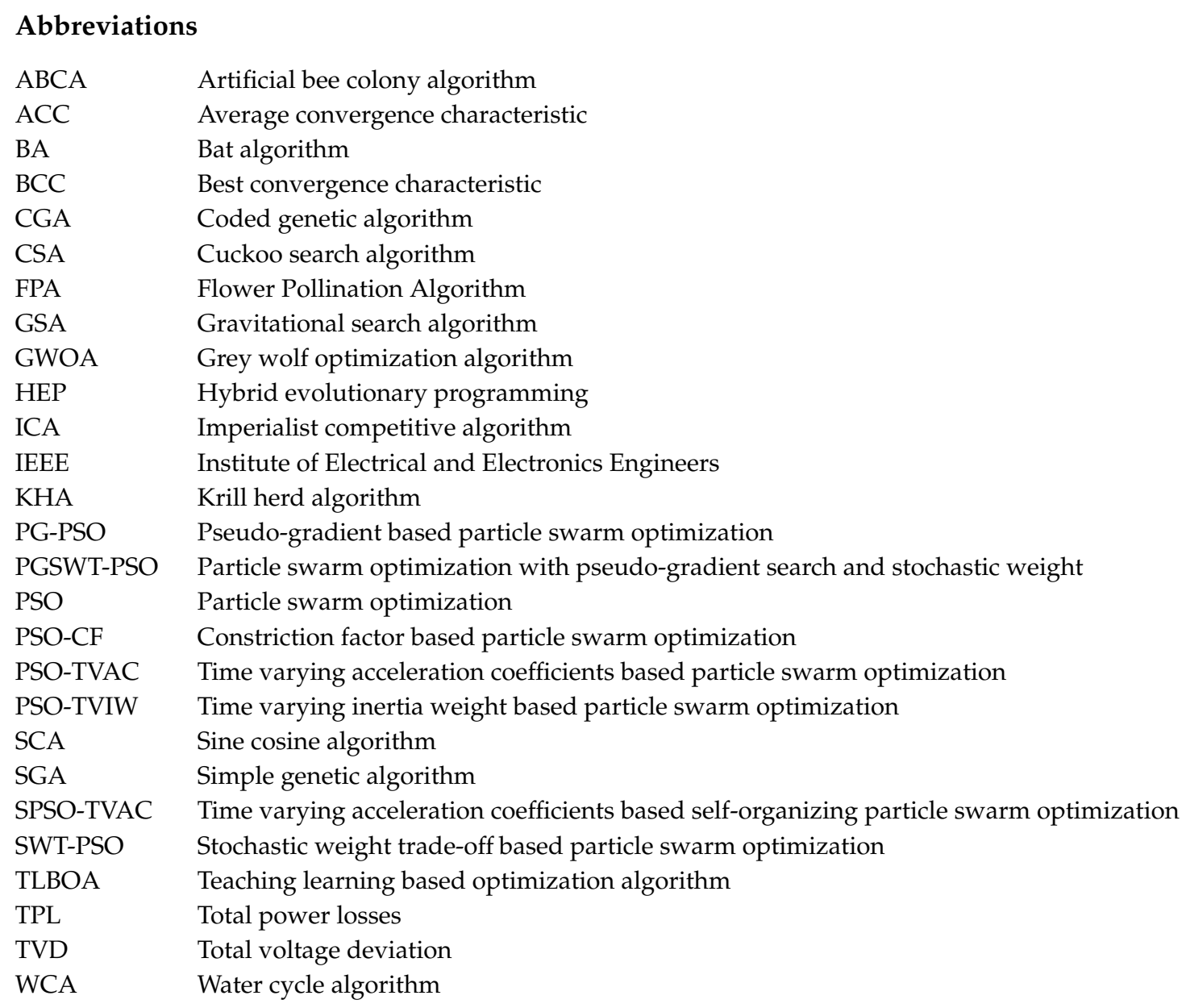




\section{Nomenclature}

\begin{tabular}{|c|c|}
\hline$A L_{\min }, A L_{\max }$ & Lower and upper bounds of $N$ variables \\
\hline$A L_{\text {rou }}$ & Position of antlion selected by roulette wheel \\
\hline$A L_{S}$ & Position of sth antlion in the search space \\
\hline$A L_{s}$ & Position of the $s$ th antlion \\
\hline$A n t_{S}$ & Position of the sth ant \\
\hline Ant $_{S}$ & Practical position of ant $s$ in the search space \\
\hline$A P_{d k}, R P_{d k}$ & Active and reactive power of the $k$ th load bus \\
\hline$A P_{G k}, R P_{G k}$ & Active and reactive power of the $k$ th generator \\
\hline$A P_{G k, \min }, A P_{G k, \max }$ & Lower and upper bounds of active power of generator bus $k$ \\
\hline Fit $A_{S}$ & Fitness function of the sth ant \\
\hline Fit $_{s}$ & Fitness function of the sth ant \\
\hline$g_{k j}$ & Line conductance between buses $k$ and $j$ \\
\hline$G_{k j}, B_{k j}$ & Real and imaginary components of admittance between bus $k$ and bus $j$ \\
\hline$I E P_{S}$ & Individual error percent between the best fitness and the fitness of antlion s \\
\hline IT & Current iteration \\
\hline$I T_{\max }$ & Maximum number of iterations \\
\hline$K_{1}, K_{2}, K_{3}$ & Penalty factors \\
\hline L-index & Maximum voltage stability index of all buses \\
\hline$L_{k}$ & Voltage stability index of the $k$ th bus \\
\hline MEP & Mean error percent between the best fitness and the average fitness of all antlion \\
\hline$N_{B}$ & Number of all buses \\
\hline$N_{\text {branch }}$ & Number of transmission lines \\
\hline$N_{C}$ & Number of capacitor banks \\
\hline$N_{C V}$ & Number of control variables \\
\hline$N_{G}$ & Number of generators \\
\hline$N_{L}$ & Number of load buses \\
\hline$N_{\text {nus }}$ & Number of newly updated solutions \\
\hline$N_{p}$ & Population \\
\hline$N_{T}$ & Number of transformers \\
\hline Objective $_{\mathrm{s}}$ & Objective function value of the sth solution \\
\hline$R P_{c k}$ & Reactive power of shunt VAR compensator at the $k$ th bus \\
\hline$R P_{c k, \min }, R P_{c k, \max }$ & Minimum and maximum reactive power of shunt VAR compensator at the $k$ th bus \\
\hline$R P_{G k, \min }, R P_{G k, \max }$ & Minimum and maximum reactive power of the $k$ th generator \\
\hline$R W_{s}$ & Random walk for the sth ant \\
\hline$R W_{s, \min }, R W_{s, \max }$ & Lower and upper limitations of random walk of the sth ant \\
\hline$S_{b, \max }$ & Maximum apparent power flow on the $b$ th branch \\
\hline$T_{k, \min }, T_{k, \max }$ & Lower and upper bounds of change of transformer's tap of the $k$ th bus \\
\hline Tol & Predetermined tolerance \\
\hline$V_{L k}$ & Relative voltage value at the $k$ th load bus \\
\hline$V o l_{G k, \min }, V_{0} l_{G k, \max }$ & Lower and upper bounds of voltage magnitude of the $k$ th generator bus \\
\hline$V_{o l} l_{k}$ & voltage magnitude of the $k$ th bus \\
\hline$V o l_{L k, \min }, V o l_{L k, \max }$ & Lower and upper bounds of voltage magnitude of the $k$ th load bus \\
\hline$V_{\text {refk }}$ & Reference voltage magnitude (normally $1.0 \mathrm{pu}$ ) at bus $k$ \\
\hline$X E_{s}^{I T}$ & Position of ant $s$ in pit of the best antlion \\
\hline$X A_{S}^{I T}$ & Position of ant $s$ in pit of the sth antlion selected by roulette wheel \\
\hline$X A_{s, \min }^{I T}, X A_{s, \max }^{I T}$ & Lower and upper bounds of $N$ variables of the sth ant at the ITth iteration \\
\hline$Y_{k j}$ & Mutual admittance between bus $k$ and bus $j$ \\
\hline & The deviating angular between buses $k$ and $j$ \\
\hline$G_{k j}, B_{k j}$ & Real and imaginary components of admittance between bus $k$ and bus $j$ \\
\hline
\end{tabular}




\section{Appendix A}

Table A1. Optimal solutions obtained by the proposed IALO method for the IEEE 30-bus system.

\begin{tabular}{cccc}
\hline Input/Control Variables & Minimize TPL & Minimize TVD & Minimize L-Index \\
\hline $\mathrm{V}_{\mathrm{G} 1}(\mathrm{pu})$ & 1.1 & 1.0999 & 1.0101 \\
$\mathrm{~V}_{\mathrm{G} 2}$ & 1.0938 & 1.0947 & 1.0051 \\
$\mathrm{~V}_{\mathrm{G} 5}$ & 1.0733 & 1.0987 & 1.0193 \\
$\mathrm{~V}_{\mathrm{G} 8}$ & 1.076 & 1.0814 & 1.0101 \\
$\mathrm{~V}_{\mathrm{G} 11}$ & 1.0999 & 1.1 & 1.0013 \\
$\mathrm{~V}_{\mathrm{G} 13}$ & 1.1 & 1.1 & 1.01 \\
$\mathrm{Q}_{\mathrm{C} 10}(\mathrm{MVAR})$ & 4.9554 & 0.5071 & 4.9879 \\
$\mathrm{Q}_{\mathrm{C} 12}$ & 5 & 0.6712 & 4.8815 \\
$\mathrm{Q}_{\mathrm{C} 15}$ & 5 & 2.6526 & 4.6286 \\
$\mathrm{Q}_{\mathrm{C} 17}$ & 5 & 1.4524 & 0.0435 \\
$\mathrm{Q}_{\mathrm{C} 20}$ & 3.8685 & 1.0391 & 4.995 \\
$\mathrm{Q}_{\mathrm{C} 21}$ & 5 & 4.9339 & 4.9367 \\
$\mathrm{Q}_{\mathrm{C} 23}$ & 2.8684 & 0.3207 & 5 \\
$\mathrm{Q}_{\mathrm{C} 24}$ & 4.9993 & 0.4495 & 5 \\
$\mathrm{Q}_{\mathrm{C} 29}$ & 2.5731 & 1.2862 & 2.9393 \\
$\mathrm{~T}_{11}$ & 1.044 & 0.9827 & 1.0149 \\
$\mathrm{~T}_{12}$ & 0.9008 & 0.9004 & 0.9002 \\
$\mathrm{~T}_{15}$ & 0.9791 & 0.9561 & 0.9848 \\
$\mathrm{~T}_{36}$ & 0.9676 & 0.9518 & 0.9695 \\
\hline
\end{tabular}

Table A2. Optimal solutions obtained by the proposed IALO method for the IEEE 57-bus system.

\begin{tabular}{ccc}
\hline Input/Control Variables & Minimize TPL & Minimize TVD \\
\hline $\mathrm{V}_{\mathrm{G} 1}(\mathrm{pu})$ & 1.1 & 1.0154 \\
$\mathrm{~V}_{\mathrm{G} 2}$ & 1.0982 & 0.971 \\
$\mathrm{~V}_{\mathrm{G} 3}$ & 1.0869 & 1.0128 \\
$\mathrm{~V}_{\mathrm{G} 6}$ & 1.0803 & 1.0033 \\
$\mathrm{~V}_{\mathrm{G} 8}$ & 1.1 & 1.0182 \\
$\mathrm{~V}_{\mathrm{G} 9}$ & 1.083 & 1.0319 \\
$\mathrm{~V}_{\mathrm{G} 12}$ & 1.0784 & 1.0106 \\
$\mathrm{Q}_{\mathrm{C} 18}(\mathrm{MVAR})$ & 10 & 0 \\
$\mathrm{Q}_{\mathrm{C} 25}$ & 5.8993 & 5.8009 \\
$\mathrm{Q}_{\mathrm{C} 53}$ & 6.293 & 6.2833 \\
$\mathrm{~T}_{19}$ & 0.8701 & 1.0199 \\
$\mathrm{~T}_{20}$ & 1.0978 & 0.9424 \\
$\mathrm{~T}_{31}$ & 1.0031 & 0.9765 \\
$\mathrm{~T}_{35}$ & 0.922 & 0.9924 \\
$\mathrm{~T}_{36}$ & 0.9825 & 0.9563 \\
$\mathrm{~T}_{37}$ & 0.9985 & 1.0309 \\
$\mathrm{~T}_{41}$ & 0.9778 & 0.9591 \\
$\mathrm{~T}_{46}$ & 0.9405 & 0.9258 \\
$\mathrm{~T}_{54}$ & 0.9072 & 0.8 \\
$\mathrm{~T}_{58}$ & 0.973 & 0.9566 \\
$\mathrm{~T}_{59}$ & 0.9628 & 0.9989 \\
$\mathrm{~T}_{65}$ & 0.9773 & 1.0163 \\
$\mathrm{~T}_{66}$ & 0.9378 & 0.8516 \\
$\mathrm{~T}_{71}$ & 0.9684 & 1.0087 \\
$\mathrm{~T}_{73}$ & 0.9955 & 0.9426 \\
$\mathrm{~T}_{76}$ & 0.962 & 0.9976 \\
$\mathrm{~T}_{80}$ & 0.9784 &
\end{tabular}


Table A3. Optimal solution obtained by the proposed IALO method for the TPL objective of the IEEE 118-bus system.

\begin{tabular}{|c|c|c|c|c|c|}
\hline \multirow{2}{*}{$\begin{array}{c}\text { Input/Control } \\
\text { Variables }\end{array}$} & \multirow{2}{*}{ Value } & \multirow{2}{*}{$\begin{array}{c}\text { Input/Control } \\
\text { Variables }\end{array}$} & \multirow{2}{*}{ Value } & \multirow{2}{*}{$\begin{array}{c}\text { Input/Control } \\
\text { Variables }\end{array}$} & \multirow{2}{*}{ Value } \\
\hline & & & & & \\
\hline $\mathrm{V}_{\mathrm{G} 1(\mathrm{pu})}$ & 1.0302 & $\mathrm{~V}_{\mathrm{G} 62}$ & 1.0424 & $\mathrm{~V}_{\mathrm{G} 113}$ & 1.0435 \\
\hline $\mathrm{V}_{\mathrm{G} 4}$ & 1.0469 & $\mathrm{~V}_{\mathrm{G} 65}$ & 1.0532 & $\mathrm{~V}_{\mathrm{G} 116}$ & 1.0485 \\
\hline $\mathrm{V}_{\mathrm{G} 6}$ & 1.0395 & $\mathrm{~V}_{\mathrm{G} 66}$ & 1.0669 & $\mathrm{Q}_{\mathrm{C5}}$ (MVAR) & -38.1239 \\
\hline $\mathrm{V}_{\mathrm{G} 8}$ & 1.0214 & $v_{\mathrm{G} 69}$ & 1.07 & $\mathrm{Q}_{\mathrm{C} 34}$ & 13.9061 \\
\hline $\mathrm{v}_{\mathrm{G} 10}$ & 1.057 & $\mathrm{~V}_{\mathrm{G} 70}$ & 1.0367 & $\mathrm{Q}_{\mathrm{C} 37}$ & -24.9417 \\
\hline $\mathrm{V}_{\mathrm{G} 12}$ & 1.0382 & $\mathrm{v}_{\mathrm{G} 72}$ & 1.0355 & $\mathrm{Q}_{\mathrm{C} 44}$ & 9.9999 \\
\hline $\mathrm{V}_{\mathrm{G} 15}$ & 1.0357 & $\mathrm{~V}_{\mathrm{G} 73}$ & 1.0336 & $\mathrm{Q}_{\mathrm{C} 45}$ & 9.3003 \\
\hline $\mathrm{V}_{\mathrm{G} 18}$ & 1.0396 & $\mathrm{~V}_{\mathrm{G} 74}$ & 1.023 & $\mathrm{Q}_{\mathrm{C} 46}$ & 10 \\
\hline $\mathrm{V}_{\mathrm{G} 19}$ & 1.0398 & $V_{G 76}$ & 1.0218 & $\mathrm{Q}_{\mathrm{C} 48}$ & 6.8292 \\
\hline $\mathrm{V}_{\mathrm{G} 24}$ & 1.0386 & $\mathrm{v}_{\mathrm{G} 77}$ & 1.0387 & $\mathrm{Q}_{\mathrm{C} 74}$ & 6.3917 \\
\hline $\mathrm{V}_{\mathrm{G} 25}$ & 1.0712 & $\mathrm{v}_{\mathrm{G} 80}$ & 1.0514 & $\mathrm{Q}_{\mathrm{C} 79}$ & 19.9965 \\
\hline $\mathrm{V}_{\mathrm{G} 26}$ & 1.1 & $\mathrm{v}_{\mathrm{G} 85}$ & 1.0455 & $\mathrm{Q}_{\mathrm{C} 82}$ & 0.0023 \\
\hline $\mathrm{V}_{\mathrm{G} 27}$ & 1.0452 & $\mathrm{~V}_{\mathrm{G} 87}$ & 1.0222 & $\mathrm{Q}_{\mathrm{C} 83}$ & 9.9982 \\
\hline $\mathrm{V}_{\mathrm{G} 31}$ & 1.0418 & $\mathrm{~V}_{\mathrm{G} 89}$ & 1.0664 & $\mathrm{Q}_{\mathrm{C} 105}$ & 15.4703 \\
\hline $\mathrm{V}_{\mathrm{G} 32}$ & 1.0382 & $\mathrm{~V}_{\mathrm{G} 90}$ & 1.0416 & $\mathrm{Q}_{\mathrm{C} 107}$ & 3.4948 \\
\hline$V_{\mathrm{G} 34}$ & 1.0418 & $\mathrm{~V}_{\mathrm{G} 91}$ & 1.0416 & $\mathrm{Q}_{\mathrm{C} 110}$ & 1.1572 \\
\hline $\mathrm{V}_{\mathrm{G} 36}$ & 1.0389 & $\mathrm{~V}_{\mathrm{G} 92}$ & 1.056 & $\mathrm{~T}_{8}(\mathrm{pu})$ & 0.9575 \\
\hline $\mathrm{V}_{\mathrm{G} 40}$ & 1.0227 & $\mathrm{~V}_{\mathrm{G} 99}$ & 1.0402 & $\mathrm{~T}_{32}$ & 1.0994 \\
\hline $\mathrm{V}_{\mathrm{G} 42}$ & 1.0315 & $\mathrm{~V}_{\mathrm{G} 100}$ & 1.0482 & $\mathrm{~T}_{36}$ & 0.992 \\
\hline $\mathrm{V}_{\mathrm{G} 46}$ & 1.0418 & $\mathrm{~V}_{\mathrm{G} 103}$ & 1.0388 & $\mathrm{~T}_{51}$ & 0.9696 \\
\hline $\mathrm{V}_{\mathrm{G} 49}$ & 1.0523 & $\mathrm{~V}_{\mathrm{G} 104}$ & 1.0341 & $\mathrm{~T}_{93}$ & 0.9594 \\
\hline $\mathrm{V}_{\mathrm{G} 54}$ & 1.0338 & $\mathrm{~V}_{\mathrm{G} 105}$ & 1.0293 & $\mathrm{~T}_{95}$ & 0.9934 \\
\hline $\mathrm{V}_{\mathrm{G} 55}$ & 1.0307 & $\mathrm{~V}_{\mathrm{G} 107}$ & 1.0156 & $\mathrm{~T}_{102}$ & 1.0884 \\
\hline$v_{G 56}$ & 1.0329 & $\mathrm{~V}_{\mathrm{G} 110}$ & 1.0258 & $\mathrm{~T}_{107}$ & 0.922 \\
\hline $\mathrm{V}_{\mathrm{G} 59}$ & 1.0575 & $\mathrm{~V}_{\mathrm{G} 111}$ & 1.0328 & $\mathrm{~T}_{127}$ & 0.9734 \\
\hline $\mathrm{V}_{\mathrm{G} 61}$ & 1.0521 & $\mathrm{~V}_{\mathrm{G} 112}$ & 1.0113 & & \\
\hline
\end{tabular}

Table A4. Optimal solution obtained by the proposed IALO method for the TVD objective of the IEEE 118-bus system.

\begin{tabular}{|c|c|c|c|c|c|}
\hline Input/Control & \multirow{2}{*}{ Value } & \multirow{2}{*}{$\begin{array}{c}\text { Input/Control } \\
\text { Variables }\end{array}$} & \multirow{2}{*}{ Value } & \multirow{2}{*}{$\begin{array}{c}\text { Input/Control } \\
\text { Variables }\end{array}$} & \multirow{2}{*}{ Value } \\
\hline Variables & & & & & \\
\hline $\mathrm{V}_{\mathrm{G} 1(\mathrm{pu})}$ & 1.0035 & $\mathrm{~V}_{\mathrm{G} 62}$ & 0.9572 & $\mathrm{~V}_{\mathrm{G} 113}$ & 1.0112 \\
\hline $\mathrm{V}_{\mathrm{G} 4}$ & 1.0047 & $\mathrm{~V}_{\mathrm{G} 65}$ & 1.0487 & $\mathrm{~V}_{\mathrm{G} 116}$ & 0.9943 \\
\hline $\mathrm{V}_{\mathrm{G} 6}$ & 0.9941 & $\mathrm{~V}_{\mathrm{G} 66}$ & 1.0475 & $\mathrm{Q}_{\mathrm{C} 5}$ (MVAR) & -23.9108 \\
\hline $\mathrm{V}_{\mathrm{G} 8}$ & 0.9691 & $\mathrm{~V}_{\mathrm{G} 69}$ & 0.9622 & $\mathrm{Q}_{\mathrm{C} 34}$ & 5.2041 \\
\hline $\mathrm{V}_{\mathrm{G} 10}$ & 1.0159 & $\mathrm{~V}_{\mathrm{G} 70}$ & 1.0318 & $\mathrm{Q}_{\mathrm{C} 37}$ & -24.8573 \\
\hline $\mathrm{V}_{\mathrm{G} 12}$ & 1.011 & $\mathrm{~V}_{\mathrm{G} 72}$ & 0.9588 & $\mathrm{Q}_{\mathrm{C} 44}$ & 7.6446 \\
\hline $\mathrm{V}_{\mathrm{G} 15}$ & 1.0017 & $\mathrm{~V}_{\mathrm{G} 73}$ & 0.9689 & $\mathrm{Q}_{\mathrm{C} 45}$ & 9.9159 \\
\hline $\mathrm{V}_{\mathrm{G} 18}$ & 0.9851 & $\mathrm{~V}_{\mathrm{G} 74}$ & 1.0123 & $\mathrm{Q}_{\mathrm{C} 46}$ & 9.9984 \\
\hline $\mathrm{V}_{\mathrm{G} 19}$ & 1.0335 & $\mathrm{~V}_{\mathrm{G} 76}$ & 1.0141 & $\mathrm{Q}_{\mathrm{C} 48}$ & 0.6712 \\
\hline $\mathrm{V}_{\mathrm{G} 24}$ & 1.0314 & $\mathrm{~V}_{\mathrm{G} 77}$ & 1.0062 & $\mathrm{Q}_{\mathrm{C} 74}$ & 11.9865 \\
\hline $\mathrm{V}_{\mathrm{G} 25}$ & 0.9555 & $\mathrm{~V}_{\mathrm{G} 80}$ & 1.0216 & $\mathrm{Q}_{\mathrm{C} 79}$ & 5.7315 \\
\hline $\mathrm{V}_{\mathrm{G} 26}$ & 0.9728 & $\mathrm{~V}_{\mathrm{G} 85}$ & 1.0131 & $Q_{C 82}$ & 19.1521 \\
\hline $\mathrm{V}_{\mathrm{G} 27}$ & 1.0079 & $\mathrm{~V}_{\mathrm{G} 87}$ & 1.0019 & $Q_{C 83}$ & 9.9215 \\
\hline $\mathrm{V}_{\mathrm{G} 31}$ & 1.0029 & $\mathrm{~V}_{\mathrm{G} 89}$ & 1.0063 & $\mathrm{Q}_{\mathrm{C} 105}$ & 14.5883 \\
\hline $\mathrm{V}_{\mathrm{G} 32}$ & 1.0025 & $\mathrm{~V}_{\mathrm{G} 90}$ & 1.088 & $\mathrm{Q}_{\mathrm{C} 107}$ & 5.6001 \\
\hline $\mathrm{V}_{\mathrm{G} 34}$ & 1.0116 & $\mathrm{~V}_{\mathrm{G} 91}$ & 0.951 & $\mathrm{Q}_{\mathrm{C} 110}$ & 5.9861 \\
\hline $\mathrm{V}_{\mathrm{G} 36}$ & 0.998 & $\mathrm{~V}_{\mathrm{G} 92}$ & 1.0038 & $\mathrm{~T}_{8}(\mathrm{pu})$ & 0.9896 \\
\hline $\mathrm{V}_{\mathrm{G} 40}$ & 1.0037 & $\mathrm{~V}_{\mathrm{G} 99}$ & 0.95 & $\mathrm{~T}_{32}$ & 1.0338 \\
\hline $\mathrm{V}_{\mathrm{G} 42}$ & 1.0176 & $\mathrm{~V}_{\mathrm{G} 100}$ & 1.0261 & $\mathrm{~T}_{36}$ & 1.0251 \\
\hline $\mathrm{V}_{\mathrm{G} 46}$ & 1.0397 & $\mathrm{~V}_{\mathrm{G} 103}$ & 1.0896 & $\mathrm{~T}_{51}$ & 0.9586 \\
\hline $\mathrm{V}_{\mathrm{G} 49}$ & 1.0037 & $\mathrm{~V}_{\mathrm{G} 104}$ & 0.95 & $\mathrm{~T}_{93}$ & 1.0462 \\
\hline $\mathrm{V}_{\mathrm{G} 54}$ & 1.0235 & $\mathrm{~V}_{\mathrm{G} 105}$ & 1.0073 & $\mathrm{~T}_{95}$ & 0.9408 \\
\hline $\mathrm{V}_{\mathrm{G} 55}$ & 1.057 & $\mathrm{~V}_{\mathrm{G} 107}$ & 1.0029 & $\mathrm{~T}_{102}$ & 0.9878 \\
\hline $\mathrm{V}_{\mathrm{G} 56}$ & 1.0156 & $\mathrm{~V}_{\mathrm{G} 110}$ & 0.9943 & $\mathrm{~T}_{107}$ & 0.9511 \\
\hline $\mathrm{V}_{\mathrm{G} 59}$ & 0.9606 & $\mathrm{~V}_{\mathrm{G} 111}$ & 0.9599 & $\mathrm{~T}_{127}$ & 0.964 \\
\hline $\mathrm{V}_{\mathrm{G} 61}$ & 1.0162 & $\mathrm{~V}_{\mathrm{G} 112}$ & 0.9503 & & \\
\hline
\end{tabular}


Table A5. Optimal solution obtained by the proposed IALO method for the L-index objective of the IEEE 118-bus system.

\begin{tabular}{|c|c|c|c|c|c|}
\hline Input/Control & \multirow{2}{*}{ Value } & Input/Control & \multirow{2}{*}{ Value } & Input/Control & \multirow{2}{*}{ Value } \\
\hline Variables & & Variables & & Variables & \\
\hline $\mathrm{V}_{\mathrm{G} 1}(\mathrm{pu})$ & 1.0287 & $\mathrm{~V}_{\mathrm{G} 62}$ & 1.0286 & $\mathrm{~V}_{\mathrm{G} 113}$ & 0.9516 \\
\hline $\mathrm{V}_{\mathrm{G} 4}$ & 0.9625 & $\mathrm{~V}_{\mathrm{G} 65}$ & 1.0372 & $\mathrm{~V}_{\mathrm{G} 116}$ & 1.0146 \\
\hline $\mathrm{V}_{\mathrm{G} 6}$ & 0.9964 & $\mathrm{~V}_{\mathrm{G} 66}$ & 0.9692 & $\mathrm{Q}_{\mathrm{C} 5}$ (MVAR) & -2.4587 \\
\hline $\mathrm{V}_{\mathrm{G} 8}$ & 1.0238 & $\mathrm{~V}_{\mathrm{G} 69}$ & 0.9559 & $\mathrm{Q}_{\mathrm{C} 34}$ & 12.654 \\
\hline $\mathrm{V}_{\mathrm{G} 10}$ & 1.0211 & $\mathrm{~V}_{\mathrm{G} 70}$ & 1.0545 & $\mathrm{Q}_{\mathrm{C} 37}$ & -21.6598 \\
\hline $\mathrm{V}_{\mathrm{G} 12}$ & 1.0304 & $\mathrm{~V}_{\mathrm{G} 72}$ & 1.0858 & $\mathrm{Q}_{\mathrm{C} 44}$ & 4.7204 \\
\hline $\mathrm{V}_{\mathrm{G} 15}$ & 1.0373 & $\mathrm{~V}_{\mathrm{G} 73}$ & 0.9725 & $\mathrm{Q}_{\mathrm{C} 45}$ & 6.6188 \\
\hline $\mathrm{V}_{\mathrm{G} 18}$ & 1.0088 & $\mathrm{~V}_{\mathrm{G} 74}$ & 0.9929 & $\hat{Q}_{\mathrm{C} 46}$ & 0.2269 \\
\hline $\mathrm{V}_{\mathrm{G} 19}$ & 1.0518 & $\mathrm{~V}_{\mathrm{G} 76}$ & 0.9544 & $\mathrm{Q}_{\mathrm{C} 48}$ & 0 \\
\hline $\mathrm{V}_{\mathrm{G} 24}$ & 1.1 & $\mathrm{~V}_{\mathrm{G} 77}$ & 1.0055 & $\mathrm{Q}_{\mathrm{C} 74}$ & 12 \\
\hline $\mathrm{V}_{\mathrm{G} 25}$ & 1.0161 & $\mathrm{~V}_{\mathrm{G} 80}$ & 1.0402 & $\widehat{Q}_{\mathrm{C} 79}$ & 15.6268 \\
\hline $\mathrm{V}_{\mathrm{G} 26}$ & 1.0913 & $\mathrm{~V}_{\mathrm{G} 85}$ & 1.0056 & $\mathrm{Q}_{\mathrm{C} 82}$ & 6.1906 \\
\hline $\mathrm{V}_{\mathrm{G} 27}$ & 1.0609 & $\mathrm{~V}_{\mathrm{G} 87}$ & 0.9953 & $\hat{Q}_{\mathrm{C} 83}$ & 1.7798 \\
\hline $\mathrm{V}_{\mathrm{G} 31}$ & 0.9611 & $\mathrm{~V}_{\mathrm{G} 89}$ & 1.0716 & $\mathrm{Q}_{\mathrm{C} 105}$ & 19.6022 \\
\hline $\mathrm{V}_{\mathrm{G} 32}$ & 0.9504 & $\mathrm{~V}_{\mathrm{G} 90}$ & 1.0223 & $\mathrm{Q}_{\mathrm{C} 107}$ & 5.8634 \\
\hline $\mathrm{V}_{\mathrm{G} 34}$ & 1.061 & $\mathrm{~V}_{\mathrm{G} 91}$ & 0.95 & $\mathrm{Q}_{\mathrm{C} 110}$ & 5.9739 \\
\hline $\mathrm{V}_{\mathrm{G} 36}$ & 1.0082 & $\mathrm{~V}_{\mathrm{G} 92}$ & 1.0385 & $\mathrm{~T}_{8}(\mathrm{pu})$ & 1.1 \\
\hline $\mathrm{V}_{\mathrm{G} 40}$ & 0.9831 & $\mathrm{~V}_{\mathrm{G} 99}$ & 1.0911 & $\mathrm{~T}_{32}$ & 0.9388 \\
\hline $\mathrm{V}_{\mathrm{G} 42}$ & 1.0254 & $\mathrm{~V}_{\mathrm{G} 100}$ & 0.95 & $\mathrm{~T}_{36}$ & 0.9506 \\
\hline $\mathrm{V}_{\mathrm{G} 46}$ & 1.1 & $\mathrm{~V}_{\mathrm{G} 103}$ & 0.9504 & $\mathrm{~T}_{51}$ & 0.986 \\
\hline $\mathrm{V}_{\mathrm{G} 49}$ & 1.0444 & $\mathrm{~V}_{\mathrm{G} 104}$ & 0.9537 & $\mathrm{~T}_{93}$ & 0.9504 \\
\hline $\mathrm{V}_{\mathrm{G} 54}$ & 1.0551 & $\mathrm{~V}_{\mathrm{G} 105}$ & 0.9502 & $\mathrm{~T}_{95}$ & 0.9837 \\
\hline $\mathrm{V}_{\mathrm{G} 55}$ & 1.0672 & $\mathrm{~V}_{\mathrm{G} 107}$ & 1.0683 & $\mathrm{~T}_{102}$ & 1.0077 \\
\hline $\mathrm{V}_{\mathrm{G} 56}$ & 1.0325 & $\mathrm{~V}_{\mathrm{G} 110}$ & 0.9576 & $\mathrm{~T}_{107}$ & 1.0969 \\
\hline $\mathrm{V}_{\mathrm{G} 59}$ & 0.9661 & $\mathrm{~V}_{\mathrm{G} 111}$ & 0.9739 & $\mathrm{~T}_{127}$ & 1.0099 \\
\hline $\mathrm{V}_{\mathrm{G} 61}$ & 0.9853 & $\mathrm{~V}_{\mathrm{G} 112}$ & 0.9655 & & \\
\hline
\end{tabular}

\section{References}

1. $\mathrm{Wu}$, Q.H.; Ma, J.T. Power system optimal reactive power dispatch using evolutionary programming. IEEE Trans. Power Syst. 1995, 10, 1243-1249. [CrossRef]

2. Yan, W.; Lu, S.; Yu, D.C. A novel optimal reactive power dispatch method based on an improved hybrid evolutionary programming technique. IEEE Trans. Power Syst. 2004, 19, 913-918. [CrossRef]

3. Varadarajan, M.; Swarup, K.S. Differential evolutionary algorithm for optimal reactive power dispatch. Int. J. Electr. Power Energy Syst. 2008, 30, 435-441. [CrossRef]

4. El Ela, A.A.; Abido, M.A.; Spea, S.R. Differential evolution algorithm for optimal reactive power dispatch. Electr. Power Syst. Res. 2011, 81, 458-464. [CrossRef]

5. Shaheen, A.M.; El-Sehiemy, R.A.; Farrag, S.M. A reactive power planning procedure considering iterative identification of VAR candidate buses. Neural Comput. Appl. 2017, 31, 653-674. [CrossRef]

6. Prasad, D.; Banerjee, A.; Singh, R.P. Optimal Reactive Power Dispatch Using Modified Differential Evolution Algorithm. In Advances in Computer, Communication and Control; Springer: Singapore, 2019; pp. 275-283. [CrossRef]

7. Wu, Q.H.; Cao, Y.J.; Wen, J.Y. Optimal reactive power dispatch using an adaptive genetic algorithm. Int. J. Electr. Power Energy Syst. 1998, 20, 563-569. [CrossRef]

8. Subbaraj, P.; Rajnarayanan, P.N. Optimal reactive power dispatch using self-adaptive real coded genetic algorithm. Electr. Power Syst. Res. 2009, 79, 374-381. [CrossRef]

9. Villa-Acevedo, W.; López-Lezama, J.; Valencia-Velásquez, J. A Novel Constraint Handling Approach for the Optimal Reactive Power Dispatch Problem. Energies 2018, 11, 2352. [CrossRef]

10. Yoshida, H.; Kawata, K.; Fukuyama, Y.; Takayama, S.; Nakanishi, Y. A particle swarm optimization for reactive power and voltage control considering voltage security assessment. IEEE Trans. Power Syst. 2000, 15, 1232-1239. [CrossRef] 
11. Singh, R.P.; Mukherjee, V.; Ghoshal, S.P. Optimal reactive power dispatch by particle swarm optimization with an aging leader and challengers. Appl. Soft Comput. 2015, 29, 298-309. [CrossRef]

12. Polprasert, J.; Ongsakul, W.; Dieu, V.N. Optimal reactive power dispatch using improved pseudo-gradient search particle swarm optimization. Electr. Power Compon. Syst. 2016, 44, 518-532. [CrossRef]

13. Mehdinejad, M.; Mohammadi-Ivatloo, B.; Dadashzadeh-Bonab, R.; Zare, K. Solution of optimal reactive power dispatch of power systems using hybrid particle swarm optimization and imperialist competitive algorithms. Int. J. Electr. Power Energy Syst. 2016, 83, 104-116. [CrossRef]

14. Dai, C.; Chen, W.; Zhu, Y.; Zhang, X. Seeker optimization algorithm for optimal reactive power dispatch. IEEE Trans. Power Syst. 2009, 24, 1218-1231. [CrossRef]

15. Khazali, A.H.; Kalantar, M. Optimal reactive power dispatch based on harmony search algorithm. Int. J. Electr. Power Energy Syst. 2011, 33, 684-692. [CrossRef]

16. Duman, S.; Sönmez, Y.; Güvenç, U.; Yörükeren, N. Optimal reactive power dispatch using a gravitational search algorithm. IET Gener. Transm. Distrib. 2012, 6, 563-576. [CrossRef]

17. Mandal, B.; Roy, P.K. Optimal reactive power dispatch using quasi-oppositional teaching learning based optimization. Int. J. Electr. Power Energy Syst. 2013, 53, 123-134. [CrossRef]

18. Mukherjee, A.; Mukherjee, V. Solution of optimal reactive power dispatch by chaotic krill herd algorithm. IET Gener. Transm. Distrib. 2015, 9, 2351-2362. [CrossRef]

19. Mouassa, S.; Bouktir, T.; Salhi, A. Ant lion optimizer for solving optimal reactive power dispatch problem in power systems. Eng. Sci. Technol. Int. J. 2017, 20, 885-895. [CrossRef]

20. Mouassa, S.; Bouktir, T. Multi-objective ant lion optimization algorithm to solve large-scale multi-objective optimal reactive power dispatch problem. Compel-Int. J. Comput. Math. Electr. Electron. Eng. 2019, 38, 304-324. [CrossRef]

21. Abaci, K.; Yamaçli, V. Optimal reactive-power dispatch using differential search algorithm. Electr. Eng. 2017, 99, 213-225. [CrossRef]

22. Shaheen, A.M.; El-Sehiemy, R.A.; Farrag, S.M. Integrated strategies of backtracking search optimizer for solving reactive power dispatch problem. IEEE Syst. J. 2018, 12, 424-433. [CrossRef]

23. Ben oualid Medani, K.; Sayah, S.; Bekrar, A. Whale optimization algorithm based optimal reactive power dispatch: A case study of the Algerian power system. Electr. Power Syst. Res. 2018, 163, 696-705. [CrossRef]

24. Heidari, A.A.; Abbaspour, R.A.; Jordehi, A.R. Gaussian bare-bones water cycle algorithm for optimal reactive power dispatch in electrical power systems. Appl. Soft Comput. 2017, 57, 657-671. [CrossRef]

25. Nuaekaew, K.; Artrit, P.; Pholdee, N.; Bureerat, S. Optimal reactive power dispatch problem using a two-archive multi-objective grey wolf optimizer. Expert Syst. Appl. 2017, 87, 79-89. [CrossRef]

26. Anbarasan, P.; Jayabarathi, T. Optimal reactive power dispatch problem solved by an improved colliding bodies optimization algorithm. In Proceedings of the 2017 IEEE International Conference on Environment and Electrical Engineering, Milan, Italy, 6-9 June 2017; pp. 1-6. [CrossRef]

27. Mei, R.N.S.; Sulaiman, M.H.; Mustaffa, Z.; Daniyal, H. Optimal reactive power dispatch solution by loss minimization using moth-flame optimization technique. Appl. Soft Comput. 2017, 59, 210-222. [CrossRef]

28. Barakat, A.F.; El-Sehiemy, R.A.; Elsaid, M.; Osman, E. Solving Reactive Power Dispatch Problem by Using JAYA Optimization Algorithm. Int. J. Eng. Res. Afr. 2018, 36, 12-24. [CrossRef]

29. Nguyen, T.T.; Vo, D.N. Improved social spider optimization algorithm for optimal reactive power dispatch problem with different objectives. Neural Comput. Appl. 2019, 31, 1-32. [CrossRef]

30. Abdel-Fatah, S.; Ebeed, M.; Kamel, S. Optimal Reactive Power Dispatch Using Modified Sine Cosine Algorithm. In Proceedings of the 2019 International Conference on Innovative Trends in Computer Engineering, Aswan, Egypt, 2-4 February 2019; pp. 510-514. [CrossRef]

31. Barakat, A.F.; El-Sehiemy, R.A.; Elsayd, M.I.; Osman, E. An Enhanced Jaya Optimization Algorithm (EJOA) for Solving Multi-Objective ORPD Problem. In Proceedings of the 2019 International Conference on Innovative Trends in Computer Engineering, Aswan, Egypt, 2-4 February 2019; pp. 479-484. [CrossRef]

32. Yalçın, E.; Taplamacıŏ̆lu, M.C.; Çam, E. The Adaptive Chaotic Symbiotic Organisms Search Algorithm Proposal for Optimal Reactive Power Dispatch Problem in Power Systems. Electrica 2019, 19, 37-47. [CrossRef]

33. Mirjalili, S. The ant lion optimizer. Adv. Eng. Softw. 2015, 83, 80-98. [CrossRef]

34. Subhashini, K.R.; Satapathy, J.K. Development of an enhanced ant lion optimization algorithm and its application in antenna array synthesis. Appl. Soft Comput. 2017, 59, 153-173. [CrossRef] 
35. Rajan, A.; Jeevan, K.; Malakar, T. Weighted elitism based Ant Lion Optimizer to solve optimum VAr planning problem. Appl. Soft Comput. 2017, 55, 352-370. [CrossRef]

36. Dinkar, S.K.; Deep, K. An efficient opposition based Lévy Flight Antlion optimizer for optimization problems. J. Comput. Sci. 2018, 29, 119-141. [CrossRef]

37. Kılıç, H.; Yüzgeç, U. Tournament selection based antlion optimization algorithm for solving quadratic assignment problem. Eng. Sci. Technol. Int. J. 2019, 22, 673-691. [CrossRef]

38. Nguyen, T.T.; Vo, D.N. Modified cuckoo search algorithm for multiobjective short-term hydrothermal scheduling. Swarm Evol. Comput. 2017, 37, 73-89. [CrossRef]

39. Nguyen, T.T.; Nguyen, T.T.; Vo, D.N. An effective cuckoo search algorithm for large-scale combined heat and power economic dispatch problem. Neural Comput. Appl. 2018, 30, 3545-3564. [CrossRef]

40. Nguyen, T.T.; Vu Quynh, N.; Duong, M.Q.; Van Dai, L. Modified differential evolution algorithm: A novel approach to optimize the operation of hydrothermal power systems while considering the different constraints and valve point loading effects. Energies 2018, 11, 540. [CrossRef]

41. MATPOWER 4.1. Available online: http://www.pserc.cornell.edu/matpower (accessed on 1 November 2018).

(C) 2019 by the authors. Licensee MDPI, Basel, Switzerland. This article is an open access article distributed under the terms and conditions of the Creative Commons Attribution (CC BY) license (http://creativecommons.org/licenses/by/4.0/). 